\title{
Ectopic pregnancy secondary to in vitro fertilisation-embryo transfer: pathogenic mechanisms and management strategies
}

\author{
Bassem Refaat $^{1^{*}}$, Elizabeth Dalton ${ }^{2}$ and William L Ledger $^{2}$
}

\begin{abstract}
Background: Ectopic pregnancy (EP) is the leading cause of maternal morbidity and mortality during the first trimester and the incidence increases dramatically with in vitro fertilisation and embryo transfer (IVF-ET). The co-existence of an EP with a viable intrauterine pregnancy (IUP) is known as heterotopic pregnancy (HP) affecting about $1 \%$ of patients during assisted conception. EP/HP can cause significant morbidity and occasional mortality and represent diagnostic and therapeutic challenges, particularly during fertility treatment. Many risk factors related to IVF-ET techniques and the cause of infertility have been documented. The combination of transvaginal ultrasound (TVS) and serum human chorionic gonadotrophin (hCG) is the most reliable diagnostic tool, with early diagnosis of EP/HP permitting conservative management. This review describes the risk factors, diagnostic modalities and treatment approaches of EP/HP during IVF-ET and also their impact on subsequent fertility treatment.
\end{abstract}

Methods: The scientific literature was searched for studies investigating EP/HP during IVF-ET. Publications in English and within the past 6 years were mostly selected.

Results: A history of tubal infertility, pelvic inflammatory disease and specific aspects of embryo transfer technique are the most significant risk factors for later EP. Early measurement of serum hCG and performance of TVS by an expert operator as early as gestational week 5 can identify cases of possible EP. These women should be closely monitored with repeated ultrasound and hCG measurement until a diagnosis is reached. Treatment must be customised to the clinical condition and future fertility requirements of the patient. In cases of HP, the viable IUP can be preserved in the majority of cases but requires early detection of HP. No apparent negative impact of the different treatment approaches for EP/HP on subsequent IVF-ET, except for risk of recurrence.

Conclusions: EP/HP are tragic events in a couple's reproductive life, and the earlier the diagnosis the better the prognosis. Due to the increase incidence following IVF-ET, there is a compelling need to develop a diagnostic biomarker/algorithm that can predict pregnancy outcome with high sensitivity and specificity before IVF-ET to prevent and/or properly manage those who are at higher risk of EP/HP.

Keywords: Ectopic pregnancy, Assisted conception, Infertility, Fallopian tube, Clinical management

\footnotetext{
* Correspondence: bassem.refaat@yahoo.co.uk

${ }^{1}$ Laboratory Medicine Department, Faculty of Applied Medical Sciences,

Umm Al-Qura University, Al-Abdiyah Campus, PO Box 7607, Makkah, KSA

Full list of author information is available at the end of the article
} 


\section{Background}

Ectopic pregnancy (EP) is a form of abnormal pregnancy in which the fertilised ovum implants outside the intrauterine cavity, with the ampullary region of the Fallopian tube being the most common site of implantation (Figure 1) [1]. EP represents 1-2\% of all pregnancies and haemorrhage from an EP due to tubal rupture remains the most common cause of maternal mortality in the first trimester of pregnancy [2].

Infertility is a problem affecting $8-12 \%$ of couples worldwide [3]. The associations between infertility and EP are complex, as one of them could be simultaneously a cause and the other a consequence $[4,5]$. There is an increased risk of developing EP following fertility treatment, which could be due to the effects of the treatment or the pre-existing disorder [6].

Since the birth of the first successful in vitro fertilisation (IVF) baby in 1978 [7], there has been an increase demand for assisted reproductive technologies (ART), including intrauterine insemination and IVF-embryo transfer (IVF-ET) with or without intracytoplasmic sperm injection [8]. Nevertheless, IVF-ET is a major risk for the development of EP and the incidence is greater by 2-3 folds than that seen in the general population. IVF may also result in a heterotopic pregnancy (HP), which is an EP together with a viable intrauterine pregnancy (IUP) [6].

Several factors related to the cause of female infertility and applied technical procedures during IVF-ET have been described as major risk factors for EP/HP. The current review discusses these risk factors, available diagnostic modalities and management approaches for the treatment of EP/HP following IVF-ET treatment, and the impact of these abnormal pregnancies and their treatment on the chances of success of subsequent fertility treatment.

\section{Methods}

'Medline' and 'EMBASE' were searched using the terms 'in vitro fertilisation', 'embryo transfer,' 'controlled ovarian stimulation,' 'risk factors', 'diagnosis', 'ultrasound,' 'human chorionic gonadotropin', 'laparotomy', 'laparoscopy', 'salpingectomy', 'salpingostomy', 'methotrexate,' 'potassium chloride,' 'hyperosmolar glucose,' 'vasopressin,' 'embryo reduction,' 'ovarian reserve' and 'pregnancy rate' in combination with 'ectopic pregnancy', 'heterotopic pregnancy', 'tubal pregnancy,' 'interstitial pregnancy,' 'ovarian pregnancy,' 'caesarean scar pregnancy', 'cervical pregnancy' or 'abdominal pregnancy' for studies published between 2004 and 2014.

Publications in English and within the past 6 years were selected, but commonly referenced and important older publications were not exclude. The reference lists of articles identified by this search strategy were also searched and those judged as relevant were also included. For a study to be included, it needed to be focused on incidence, diagnosis, clinical management and effect on subsequent IVF cycle of EP/HP during IVF-ET treatment. Studies that were solely focusing on EP following spontaneous conception were not included except of the management of HP due to its infrequency.

\section{Results}

\section{Prevalence}

EP is estimated to be $1-2 \%$ of all natural conceptions and the incidence increases following ART [4]. The prevalence of EP following ART ranges between 2.1 to $8.6 \%$ of all pregnancies and it can reach up to $11 \%$ in female patients

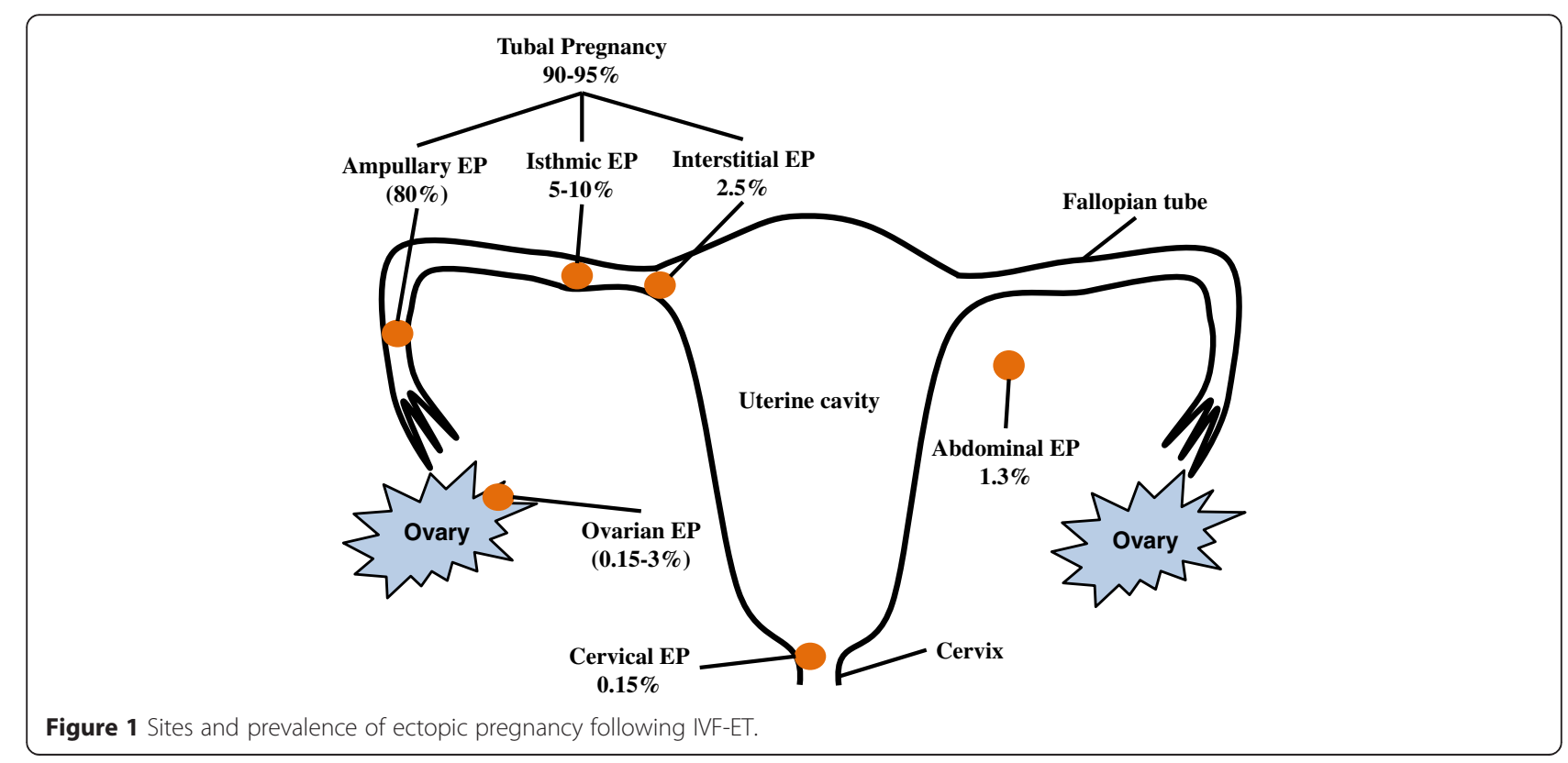


with a history of tubal factor infertility [9]. Death from EP has been reported to represent $5 \%$ and $10 \%$ of all maternal deaths in developed and developing countries, respectively [2].

Spontaneous HP was considered to be very rare with an incidence of 1 in 30,000 pregnancies. The incidence of HP has also increased following ART and it has been reported that it complicates about $0.8 \%$ of pregnancies following infertility treatment [10].

\section{Pathogenic mechanisms}

Tubal pregnancies that occurring naturally and following IVF-ET share the same tubal risk factors, suggesting that tubal damage has a predominant role in the pathogenesis of both [6]. The proposed pathogenic mechanisms associated with risk factors for EP either following natural or assisted conception are summarized in Figure 2.

Our understanding of the pathophysiology of EP is limited $[11,12]$. The current literature supports the hypothesis that the major cause of tubal implantation is malfunction of the tube itself, although embryonic and uterine factors may also be implicated. Tubal malfunction results from alterations in tubal transport mechanisms and expression of molecules that normally inhibit blastocyst implantation in the Fallopian tube [13-15].

However, in the case of EP post IVF-ET, in which passage of the embryo along the Fallopian tube does not occur, additional factors that prevent intrauterine implantation must precede ectopic implantation of the embryo. Differentiating between the mechanisms involved in natural and post IVF-ET tubal pregnancy is difficult. To our knowledge, only one study has compared tubal pathology in natural and IVF ectopic pregnancies, using E-cadherin as a marker of implantation potential [16]. Further biological studies using this comparative approach are necessary in order to elucidate the mechanisms involved.

Another explanation for EP during IVF-ET would be impairment of tubal function and endometrial receptivity with ectopic implantation occurring following failure of the normal biological interactions between endometrium, Fallopian tube and embryo due to controlled ovarian stimulation (COS) and the subsequent alteration in hormonal milieu $[17,18]$. Hence women with underlying tubal disease undertaking IVF may face a "double whammy" in

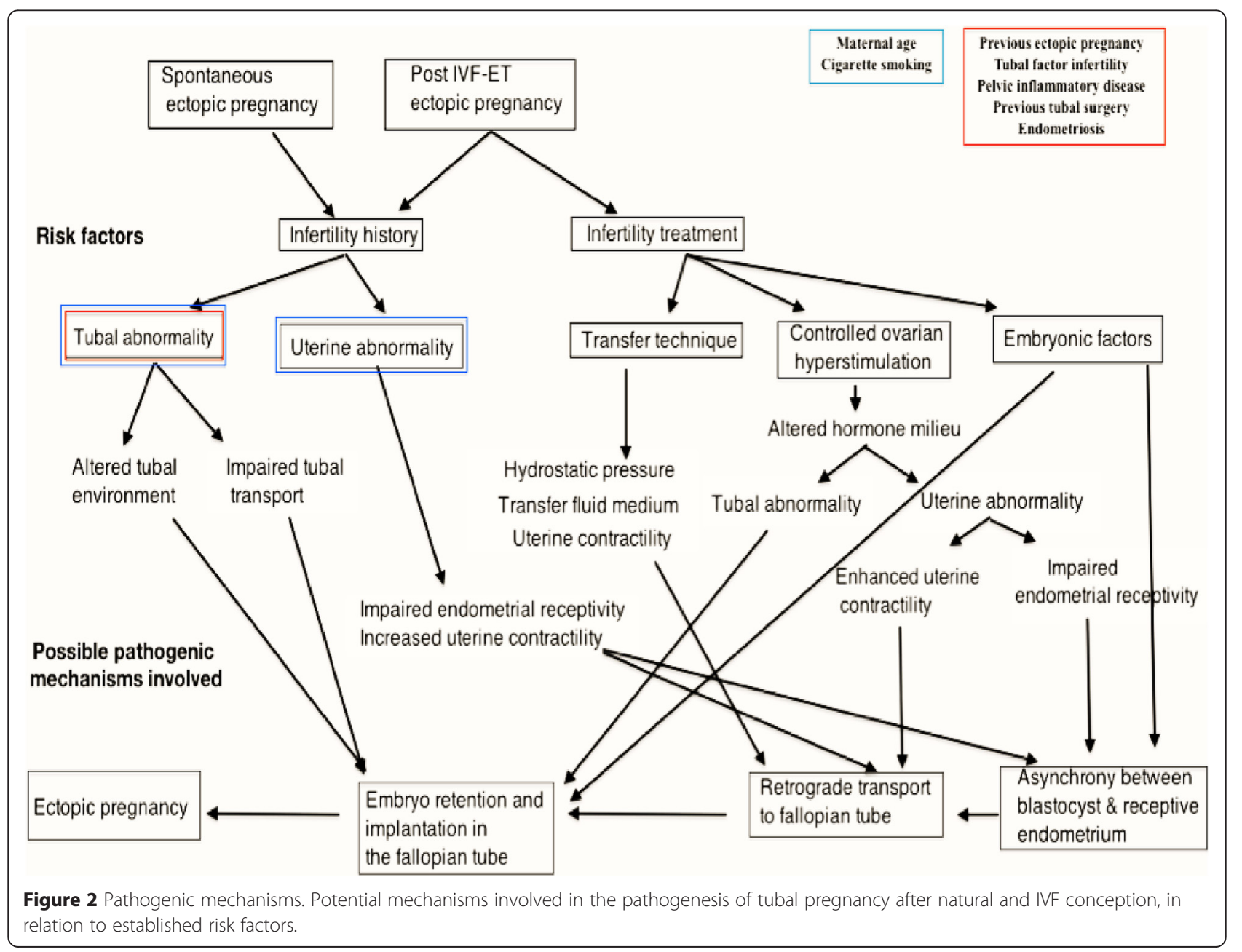


risk of EP, due both to the tubal disease and adverse effects of superovulation on tubal function during the IVF cycle.

\section{Risk factors}

Several factors increase the risk of EP following IVF-ET and they are associated either with the infertility history of the patient or specific factors related to IVF-ET techniques (Table 1).

\section{Factors related to infertility history}

The increase in the incidence of EP is associate with the use of ART. Even with a single embryo transfer, women undergoing ART treatment have a relative risk of 6.40 (95\% CI: 4.38-9.35) of developing EP compared with natural conceptions [19]. The increase in EP has been associated with several maternal risk factors, mainly related to the woman's infertility history.

\section{Maternal age}

Several research groups have shown that the risk of EP increases with advancing age, particularly in women over 35 years $[20,21]$. A steady increase was also reported in the incidence of EP with the increase in maternal age at conception from $1.4 \%$ at the age of 21 years to $6.9 \%$ in women aged 44 years or more [22]. An explanation for this trend with age could be the existence of a higher probability of exposure to most other risk factors with advancing age, increase in chromosomal abnormalities

Table 1 Risk factors for EP during IVF-ET

\begin{tabular}{|c|c|c|}
\hline & Maternal & IVF-ET Technique \\
\hline \multirow[t]{6}{*}{ Definite risks } & Tubal infertility & $\begin{array}{l}\text { High volume of transfer } \\
\text { media }\end{array}$ \\
\hline & $\begin{array}{l}\text { Pelvic inflammatory } \\
\text { disease }\end{array}$ & Multiple embryo transfer \\
\hline & History of tubal surgery & \\
\hline & $\begin{array}{l}\text { Previous ectopic } \\
\text { pregnancy }\end{array}$ & \\
\hline & Cigarette smoking & \\
\hline & Endometriosis & \\
\hline \multirow[t]{8}{*}{$\begin{array}{l}\text { Inconclusive } \\
\text { risks }\end{array}$} & Maternal age & $\begin{array}{l}\text { Controlled ovarian } \\
\text { stimulation }\end{array}$ \\
\hline & Uterine abnormalities & $\begin{array}{l}\text { Triggering oocyte } \\
\text { maturation }\end{array}$ \\
\hline & & Luteal phase support \\
\hline & & $\begin{array}{l}\text { In vitro fertilisation/ } \\
\text { maturation }\end{array}$ \\
\hline & & Assisted hatching \\
\hline & & Embryonic stage at transfer \\
\hline & & Fresh vs. Frozen embryo \\
\hline & & $\begin{array}{l}\text { Transfer technique of } \\
\text { embryo }\end{array}$ \\
\hline
\end{tabular}

Summary of definite and inconclusive risk factors for ectopic/heterotopic pregnancy during in vitro fertilisation and embryo transfer treatment. in trophoblastic tissue and age-related changes in tubal function [21].

Alternatively, other research groups have failed to detect an association between maternal age and the risk of developing EP [23-25], Further prospective studies with large numbers of participants are needed to determine whether a relation truly exists between maternal age and the risk of developing EP during IVF-ET.

\section{Tubal factor infertility}

Tubal factor infertility (TFI) is a major risk for EP when compared to other causes of infertility [6,26]. IVF-ET was originally designed to overcome TFI by placing the embryo(s) within the uterine cavity. However, it appears that the embryo, in some cases, can still enter the tube and establish an ectopic implantation [20].

TFI, compared with other causes of infertility, increases the risk of EP following IVF-ET with a prevalence of up to $11 \%$ of cases with TFI [9]. Similar results were also reported by a more recent study that examined the risk factors for EP following IVF in 712 women with an OR of 3.99 (95\% CI: 1.23 to 12.98) for women with TFI compared with those with other infertility causes [23]. Another study has also described that the OR for EP in 900 women with planned pregnancy was 8.81 (95\% CI: 1.68-21.21) for those with a history of TFI compared with 5.82 [95\% CI: 3.47, 9.78] for non-tubal infertility. However, the authors have also reported that the adjusted odd ratio (AOR) was comparable between TFI $(3.62 ; 95 \%$ CI: $1.52,8.63)$ and non-TFI $(3.34 ; 95 \%$ CI: $1.60,6.93)[25]$.

\section{Pelvic Inflammatory Disease}

A history of pelvic inflammatory disease (PID) has also been implicated in the increased incidence of EP following either natural or assisted conception [26,27]. A past history of PID is associated with a 7.5 times greater risk of developing EP [28,29].

Chlamydia trachomatis infection is the most common sexually transmitted infection worldwide [30,31]. The immune response to this infection may lead to tubal occlusion, EP and infertility $[27,32,33]$. Despite spontaneous clearance of $C$. trachomatis infection, antibodies against the organism and its heat shock protein-60 (CHSP60) remain detectable for many years. The presence of these antibodies have been strongly associated with poor reproductive outcomes, including early pregnancy loss and EP following IVF [25,32].

The presence of IgA antibodies against Chlamydia trachomatis was associated with lower implantation and pregnancy rates among 235 patients undergoing IVF [34]. Live birth rate following IVF was also found to be lower in women with cervical anti-chlamydial and antiCHSP60 IgA antibodies when compared with those who 
were negative for these antibodies [32]. Similar results were also observed for an effect on implantation rate in 253 IVF patients with follicular fluid anti-CHSP60 antibodies [35]. This is further supported by a more recent study that has shown that the risk of EP in 900 women with planned pregnancies and who had detectable $C$. trachomatis IgG was about five times of those with negative reaction (95\% CI: 3.94-7. 04) [25].

In contrast, other studies have not supported a role for previous infection with $C$. trachomatis in the development of EP [23,36,37]. One longitudinal study found that there was no significant difference in pregnancy rates for women with or without chlamydial infection at baseline [38]. Similar results were also reported for 712 IVF patients [23]. The presence of antibodies against CHSP60 among 174 women with apparently normal Fallopian tubes at laparoscopy was also not associated with lower pregnancy rates during 3 years follow-up [39]. A recent review has therefore suggested that the inconsistency in the results could be related to flaws in study design and lack of a reliable method for measuring a history of pelvic infection [13]. The authors also argued that the current assumptions on the risks of adverse outcomes following pelvic infection in subsequent pregnancy are based on retrospective case-control studies, which are prone to many confounding variables [13].

\section{Previous ectopic pregnancy}

A history of EP is considered as a major risk factor for subsequent recurrence of EP and each successive occurrence significantly increases the risk $[5,22]$. The recurrence rate ranges from 15 to $20 \%$ in the case of one previous EP treated by linear salpingostomy, depending on the integrity of the contralateral tube and it increases to $32 \%$ in cases with two previous ectopic pregnancies. However, an intervening IUP lowers this rate $[6,20,40]$.

A retrospective study measured the risk of EP following IVF in 181 women with a previous ectopic, with significantly higher risk of recurrence when compared with 377 women with other causes of infertility. The authors reported that the chance of developing EP was 45 times in the case group and the prevalence of EP was 8.95\% compared with $0.75 \%$ in the control group [24]. Similar results with an OR of 9.68 (95\% CI: 6.02-15.56) for were reported in a study of 900 EPs compared with 889 IUPs in women with planned pregnancy [25] and another study also demonstrated an OR of 57.93 (95\% CI: 6.79494.25) for developing EP in 150 women diagnosed with EP compared with 300 healthy pregnant women [21].

\section{Previous tubal surgery}

A history of tubal/pelvic surgery is another major risk factor for the development of EP following IVF, with the level of risk depending on the degree of damage and the extent of anatomic alteration [6,22]. Odds ratio for developing EP was 8.52 (95\% CI: 5.91-12.27) for prior adnexal surgery, 11.02 (95\% CI: $5.49,22.15)$ for a previous tubal infertility surgery, 5.16 (95\% CI: 1.2521.21) for prior surgery for endometriosis and 17.70 (95\% CI: 8.11-38.66) for a previous abdominal/pelvic surgery $[21,23,25]$.

Hydrosalpynx is a main cause of tubal infertility and is also associated with a negative impact on the outcome of IVF treatment. Treatment of hydrosalpynx before IVF involves radical and conservative surgical approaches [41,42]. The rate of EP has been reported to be about 9\% in patients undergoing IVF following tubal surgery for the treatment of hydrosalpinx $[43,44]$.

\section{Endometriosis}

Endometriosis and its treatment has also been associated with the development of EP $[6,25,45]$. Endometriosis leads to the formation of pelvic and tubal adhesions, which could result in abnormal tubal function. Additionally, the Fallopian tubes could also be affected by other, less clearly understood effects of endometriosis [46,47], as well as by the medications that are administered to aid ovulation and improve fertility in patients with endometriosis [23].

\section{Cigarette smoking}

Cigarette smoking increases the risk of EP after natural conception by 1.6 to 3.5 times as compared to nonsmokers, in a dose dependant manner $[25,48,49]$. Smokers also have a higher risk of developing EP following IVF treatment of about 3 times compared with non-smokers $[24,25,49]$. Laboratory studies in several species have shown that smoking decreases tubal and uterine motility [50-53].

\section{Uterine abnormalities}

Studies of the uterine factors that may be implicated in EP after IVF-ET have focused on the mechanism by which the embryo migrates into the Fallopian tube after intrauterine transfer. The possible effects of uterine abnormalities on implantation failure have not been well studied to date. A recent meta-analysis [54] concluded that "there is very little evidence that the established treatments improve outcomes, or that these pathologies have a negative effect on ART". One study has reported that intramural fibroids are associated with a higher frequency of uterine peristalsis in the peri-implantation phase [55] but further work is required. The impact of uterine pathologies on risk of EP after IVF-ET remains to be elucidated.

\section{Infertility treatment specific risk factors}

An increased incidence and unusual forms of EP have been reported after IVF-ET and, in fact, the first pregnancy reported after IVF-ET was an EP [56]. Several 
studies have investigated the development of EP during IVF-ET and many technical issues of the treatment have been proposed as risk factors for EP. These risk factors (Table 1) include an altered hormonal milieu due to $\mathrm{COS}$, the day and stage of embryo transfer, multiple embryo transfer, volume of transfer media and position of the catheter.

\section{Controlled ovarian hyperstimulation}

The alteration in the endocrine milieu in the stimulated/ fresh cycle following COS may be a potential risk factor for the development of EP during IVF-ET. Possible mechanisms involve diminished endometrial receptivity [6], which could be supported by the observations that endometrial and subendometrial blood flow on the day of human chorionic gonadotropin (hCG) injection were significantly lower in IVF patients with miscarriage and EP when compared with those with viable IUP [57].

Higher circulating concentrations of oestradiol (E2) during stimulated cycles could also be associated with a reverse migratory process of the transferred embryo(s) [58]. A recent retrospective study showed that COS in patients with polycystic ovarian syndrome (PCOS) was associated with a greater risk of EP in fresh cycles (AOR 3.06; 95\% CI: 1.34-6.96) but not with frozen-thawed embryo transfer (FTE) cycles. By further analysing the cases of EP in the non-PCOS patients, women with E2 levels $>4085 \mathrm{pg} / \mathrm{mL}$ had 2 times greater risk of developing EP (95\% CI: 1.19-3.35). Hence, the authors suggested that the observed higher prevalence of EP during COS could be related to the hyperphysiologic levels of E2 associated with PCOS and/or ovulation induction [59].

Another review has suggested that the increased concentrations of progesterone in stimulated cycles could be beneficial in promoting endometrial implantation by decreasing uterine contractions when compared with FET cycles [6]. However, a later meta-analysis has identified a lack of randomised controlled trials (RCTs). The authors recommended the conduct of appropriately powered RCTs to compare natural cycle IVF with standard IVF, with outcomes including adverse events such as EP [60].

Available information on the possible effect of luteal phase support during the fresh cycle or for endometrial preparation in FET cycles in relation to the development of EP is conflicting. A retrospective study has shown that patients with high circulating concentrations of oestrogen and progesterone on the day of hCG injection had the highest frequency of EP compared with the low E2 and low progesterone groups [61]. Similar observations were also reported by other retrospective studies showing that programmed FET cycles were associated with higher rates of EP compared with natural cycles $[62,63]$.
Conversely, a retrospective analysis of 1677 FTE cycles showed a non-significant difference in the prevalence of EP in natural versus programmed cycles [64]. This was supported by later data generated from an RCT and two retrospective studies that revealed no significant differences for use of progesterone in FET cycles in EP rates [65-67]. Several other multicentre RCTs have also measured the effect of different progesterone preparations for luteal phase support in fresh and FET cycles with no significant differences in the prevalence of EP [68-70]. Similar results were also reported by two recent metaanalyses including 91 RCTs of luteal phase support with progesterone or hCG [71,72].

In a prospective case-control study that included 100 IVF-ET cycles, a non-significant increasing trend in the prevalence of EP was observed between the use of $\mathrm{GnRH}$-agonist in combination with hCG for triggering oocyte maturation compared with use of hCG alone [73]. A different retrospective study has described the opposite effect, with significantly higher rates of EP with GnRH-agonist trigger (5.3\%) compared with recombinant hCG (1.4\%) for oocyte maturation [74]. However, a recent Cochrane review has concluded that there is a lack of evidence that either treatment used for final oocyte maturation is associated with an increased risk of developing EP [75].

The association between COS and EP is still unclear and the results of the aforementioned studies are contradictory. The currently available data on the risk of developing EP following COS are mainly derived from retrospective studies or prospective case-control studies, which do not provide high quality scientific evidence for the suggested association between COS and EP. This has been reflected in the conclusions of several systematic reviews that have evaluated the different hormones during ART with the authors consistently stating that there is a lack of high quality evidence from RCTs that include the rate of EP in their primary or secondary objectives.

The recent concept of 'individualised COS' protocol that best fit the needs of each patient [76] makes the analysis of a possible association between COS and EP out with RCTs even more difficult. Future large multicentre RCTs with control for confounding variables are still needed to reach a solid conclusion on whether COS is a risk factor for the development of EP.

\section{Embryonic factors}

Assisted hatching (AH) has been proposed as a risk factor for developing EP after IVF [6]. In a previous retrospective analysis of 623 clinical pregnancies following IVF, a 5.4\% rate of EP $(14 / 258)$ was found in cases where AH was performed compared to $2.2 \%(8 / 365)$ in the non $\mathrm{AH}$ group [77]. However, a more recent RCT showed that AH neither improved pregnancy rate nor increased risk of EP in 
121 women $<38$ years [78] and a later retrospective analysis of $1126 \mathrm{AH}$ cycles also reported that there was no effect on the prevalence of EP in an antibiotic and steroid treatment group compared with an untreated group [79]. It may be worthwhile to assess the effect of $\mathrm{AH}$ on the incidence of EP in a large multicentre study but recent evidence is against such an association.

Embryo transfer at the blastocyst stage appears to be the most biologically appropriate stage for intrauterine implantation as earlier stages of embryo development occur normally within the Fallopian tube [80]. Blastocyst transfer may also theoretically decrease the incidence of EP following IVF-ET as there may be decreased uterine contractility by day five after egg collection [81,82]. However, the potentially higher implantation rate per embryo at the blastocyst stage may increase the risk of EP compared with cleavage stage transfer [6] but a number of studies have indicated that, in practice, there is no difference in the incidence of EP between blastocyst and cleavage stage transfers $[80,82,83]$. EP rates have also been compared between frozen and fresh transfers of blastocyst with frozen transfer being shown to have the potential to decrease the frequency of EP compared with fresh transfer [62,66,84-86].

The 'quality' of the embryo may also contribute to risk of EP after IVF. Egg related factors such as chromosomal abnormalities may increase risk of EP [87] and, in a rodent study using an embryo donation model, superovulation with gonadotropins was suggested to impair blastocyst quality as well as endometrial receptivity [88]. A poor quality embryo may be less likely to undergo eutopic implantation resulting both in a decrease in the chances of establishment of an IUP and also increase in risk of EP.

Other possible embryonic factors that could induce EP following IVF include abnormal expression of adhesion molecules either by embryos fertilised in vitro or from tubal implantation sites following COS [16]. The abnormal expression has been attributed to the exposure of embryo (s) to different cytokines and growth factor milieu during in vitro culture compared with embryos conceived in vivo $[13,16]$. However, more sophisticated array studies are needed to explore possible altered expressions at the gene and protein levels by embryos following in vitro fertilisation and/or maturation.

\section{Transfer technique}

Another explanation for the development of EP following IVF-ET has been related to the induction of abnormal uterine contractions that may result in reverse migration of embryos from the uterine cavity into the Fallopian tube and ectopic implantation. Lesny et al. studied junctional zone uterine contractility during mock embryo-transfers and they reported that when the catheter was deliberately allowed to contact the uterine fundus, strong random contraction waves were observed in the fundal area and fluid was moved directly into the Fallopian tubes $[89,90]$.

Another recent study has also demonstrated that uterine peristalsis increased significantly following 30 minutes of mock ET during the luteal phase of natural cycle in 112 infertile women. The fluid movement was positively and significantly correlated with the frequency of uterine peristalsis and the fluid was moved to the cervix, Fallopian tube and extruded in 5 (4.5\%), 11 (9.8\%) and $2(1.8 \%)$ patients, respectively. The same research group later published another study on uterine peristalsis before ET in 292 infertile women undergoing fresh and FET cycles. Consistently, there was a significant negative correlation between uterine contractions and the achievement of clinical pregnancy. Moreover, uterine peristalsis $>2$ waves/minute was a major risk factor for not achieving clinical pregnancy (OR 0.49; 95\% CI: 0.34-0.70). The authors have therefore suggested that high uterine peristalsis could adversely affect embryo implantation and lead to low implantation rate and/or EP [91,92].

The technique of ET could also influence the rate of ectopic implantation due to forcing the embryo through tubal ostia by hydrostatic pressure or by using large volume of transfer medium [93-95]. Marcus et al. observed that patients having EP received a higher volume of culture medium than those having normal IUP [96]. Knutzen et al. also showed that after injecting $50 \mu \mathrm{l}$ of radio-opaque fluid through a standard ET catheter, the material was passed either totally or partially into the Fallopian tubes in $44 \%$ of patients, suggesting that the chance of the embryo being carried into the tube immediately after high volume transfer [97].

The position of transfer catheter and the distance from the fundal endometrium to either the tip of catheter or to an air bubble within the catheter have also been investigated as potential risk factors for low pregnancy rate and development of EP. An RCT showed that IUP following deep fundal transfer was $12.4 \%$ per cycle with a $1.5 \%$ EP versus $14.2 \%$ IUPs per cycle with a $0.4 \%$ ectopic rate after midfundal transfer. The midfundal technique was suggested to be superior because of a lower risk of EP without any reduction in IUP rate [94,95]. This has been further supported by Coroleu et al. (2002) who reported that the placement of the transfer catheter close to the fundus endometrial surface $(1 \mathrm{~cm})$ resulted in EP while at a distance of 15-20 millimetres from the fundus achieved higher implantation and pregnancy rates [98].

Others have recommended performing ET in a position in which the fundus is at the highest point above the horizon and to perform the transfer slowly over at least 10 seconds [99]. They also suggest that placement of the catheter tip near the fundus appeared to transfer the embryos into the tube when transfer was performed 
more quickly, possibly resulting in EP and that transfer of embryos to a standard midcavity position results in a lower EP rate [99].

However, recent reports have also suggested that an optimal transfer location of a distance $<10 \mathrm{~mm}$ and $>5 \mathrm{~mm}$ from the fundal endometrium results in higher pregnancy rates compared with groups where the tip of the transfer catheter was placed further from the fundus. There were no cases of EP [100-102].

Multiple embryo transfer has always been associated with increased risk of EP with transfer of two or less embryos carrying lower risk than after three or more [103]. The current guidelines on the number of embryos to transfer, which are based on the maternal age, could therefore decrease the incidence of EP following IVF especially in younger patients with a single embryo transfer $[103,104]$. Remarkably, a single elective embryo transfer is associated with higher risk of EP (RR 6.40; 95\% CI: 4.389.35) compared with spontaneously conceived singletons as reported by a recent meta-analysis [19]. Furthermore, a recent study by Chai et al. (2014) has shown that there was no significant difference in the frequency of EP between 74 women with single embryo transfer $(2.5 \%)$ when compared with 132 women with double embryo transfer (5.2\%) [105]. Nevertheless, single embryo transfer should be the preferred choice for all patients under 40 as it reduces risk of pregnancy complications, most notably premature birth with risk of subsequent impairment of the health of the offspring [106,107].

\section{Diagnosis of EP/HP following IVF-ET}

$\mathrm{EP} / \mathrm{HP}$ are serious complications during ART and present considerable diagnostic and therapeutic challenges. Adverse maternal outcomes may follow rupture of the EP with hypovolemic shock and blood transfusion requiring $[10,14,108]$. These events may also adversely affect the viable IUP in the case of HP. A single determination of serum hCG, even as early as 11-12 days after ET, and early transvaginal ultrasound (TVS) have been found to be predictive of pregnancy location $[109,110]$ but cannot reliably identify a viable IUP with a co-existing EP.

\section{Diagnostic modalities of EP}

Serial quantitative measurement of hCG in combination with TVS is the currently accepted paradigm for clinical diagnosis and management of EP, with hCG monitoring being used to follow patients until complete resolution of the EP $[4,5,111,112]$. TVS can effectively detect small intrauterine and ectopic pregnancies when serum hCG level is $2000 \mathrm{IU} / \mathrm{L}[4,5,112]$ due to its superior resolution [111,113].

\section{Human chorionic gonadotropin (hCG)}

Although ART procedures and/or the pre-existing disorder may affect the course of hCG concentration [114], several studies on IVF patients have reported that a single serum $\beta$-hCG assay can accurately differentiate between viable and non-viable pregnancies. However, threshold values vary between the different studies, depending mainly on the exact day of the assay in relation to the date of ET.

Measuring serum concentrations of $\beta$-hCG in the peri-implantation period (day 5 post blastocyst transfer) was highly predictive of IVF-ET outcome and was able to differentiate ongoing pregnancies from failing pregnancies, including EP [115]. Another retrospective study showed that serum $\beta$-hCG on day 12 post ET for the diagnosis of EP had a sensitivity of $82.7 \%$, specificity of $71.1 \%$, positive predictive value (PPV) $15.5 \%$ and negative predictive value (NPV) $98.5 \%$ at a cut-off of $91 \mathrm{IU} / \mathrm{L}$ [110]. Similar results were also reported in 177 IVF cycles using $80 \mathrm{mIU} / \mathrm{mL}$ as the cut-off for a positive test result yielded a $94 \%$ sensitivity, $53.4 \%$ specificity and $80 \%$ positive predictive value for live birth [116]. Serum levels of $\beta$-hCG on day 15 following oocyte retrieval were shown to be dependent on the day of ET, being significantly higher after day $5(198 \pm 10.6 \mathrm{IU} / \mathrm{L})$ compared with day $3(103.6 \pm 4.4 \mathrm{IU} / \mathrm{L})$ transfers. The authors also reported that serum $\beta$-hCG above $78 \mathrm{IU} / \mathrm{L}$ and $160 \mathrm{IU} / \mathrm{L}$ were highly predictive of ongoing pregnancy for day 3 and day 5 transfers, respectively [117]. Another retrospective study showed that serum $\beta$-hCG at a cut-off value of $377.8 \mathrm{IU} / \mathrm{L}$ on day 17 post oocyte collection generated an area under the curve of 0.730 with $75.9 \%$ sensitivity and $61.2 \%$ specificity for the diagnosis of EP [118].

\section{Ultrasound}

Ultrasound can be used to locate a pregnancy anatomically and to see if the fetus is alive. In general, a gestational sac can be consistently identified by TVS at a cut-off level of serum $\beta$-hCG is $2000 \mathrm{IU} / \mathrm{L}$, which is known as the discriminatory zone $[119,120]$.

The finding of an empty uterine cavity can be associated with a small early pregnancy, EP or miscarriage. The correlation of the sonographic finding with serum level of hCG is therefore useful for achieving accurate diagnosis. If $\beta$-hCG level is below the discriminatory level, measurement of the hormone should be repeated every 48 hours with a repeat ultrasound when the level has reached the predetermined discriminatory level [121]. However, if the $\beta$-hCG is above the predetermined threshold or if it stabilises/fails to increase normally, then the diagnosis of an EP needs to be considered [121,122].

\section{Diagnosis of HP}

$\mathrm{HP}$ is a rare but potentially life-threatening event and early diagnosis and treatment are essential in order to 
best preserve the viable IUP and avoid maternal morbidity and mortality $[122,123]$. Hence this challenging condition should be suspected in all patients who conceive following ART regardless of the presence or absence of currently recognised risk factors, particularly after transfer of multiple embryos. Investigation of the adnexa by TVS is essential to exclude the possibility of HP. A moderate or large amount of free pelvic fluid should warrant particular care when assessing the adnexa with ultrasound, even in the presence of an IUP $[124,125]$.

The diagnosis of HP is elusive and challenging due to the co-existence of the viable IUP which can generate an appropriate increase in the level of $\beta$-hCG. Thus the diagnostic value of hCG measurement is limited in cases with HP and the diagnosis is mainly dependent on the findings of TVS $[122,124]$. In a retrospective study that included a total of 184 HP following IVF-ET, 174 were diagnosed by TVS while 10 cases were missed. The three main types of ultrasonographic findings were: visualisation of extrauterine gestational sac in 57.3\%, adnexal mass in $25.4 \%$ and ring sign in $17.2 \%$ of cases. The sensitivity and specificity of TVS in the diagnosis of HP was $92.4 \%$ and $100 \%$ respectively with positive and negative predictive values of $100 \%$ and $99.9 \%$, respectively [126].

Most cases of HP are missed on initial presentation, which could be due a false sense of security provided by the sonographic finding of a viable IUP with failure to inspect the adnexa fully or the HP being too small to identify [122]. The amount of fluid in the cul-de-sac can assist in the diagnosis of HP. One study found that patients with abnormal cul-de-sac fluid were five times more likely to have HP as patients without it [127]. Causes of misdiagnosis include misidentification of an HP as a corpus luteal cyst $[122,127]$ or due to mirror image artefact on TVS due to the patient having a full bladder during the process, which causes reflection of a viable IUP on a different part of the image and could be mistakenly diagnosed as HP [128].

A retrospective study investigated $28 \mathrm{EP} / \mathrm{HP}$ that ruptured due to misdiagnosis and/or delayed management and the main factors that led to delay were insufficient training in TVS and unawareness about EP/HP by the physicians, atypical symptoms and early rupture of EP. The authors suggested that TVS should therefore be performed at week 5 of gestation followed by serial measurement of serum $\beta$-hCG and repeated ultrasonography in suspicious patients [10].

\section{Treatment}

EP is a major event in a woman's reproductive life and is particularly tragic after a long and difficult course of treatment for infertility. Counselling and psychological support should also be given alongside clinical treatment if EP occurs, especially following infertility treatment [129].
EP/HP can be treated surgically, medically and occasionally by observation alone. Treatment must be customised to the clinical condition and future fertility requirements of the patient. However, the use of conservative approaches necessitates early diagnosis of EP/HP $[130,131]$.

\section{Surgical treatment}

The traditional treatment for tubal pregnancy is laparotomy and salpingectomy. Laparoscopic approaches became more widely accepted after the development of video laparoscopy and the publication of the first series of successful use of laparoscopy for the treatment of EP in the 1980's [132]. Laparoscopic surgery is the preferred approach in haemodynamically stable patients and has largely replaced the need for laparotomy due to improved postoperative recovery time and reduced morbidity [133,134].

Laparotomy is the preferred technique when the patient is haemodynamically unstable, if the surgeon has not been trained in laparoscopy or if laparoscopic surgery equipment is not available [133-135]. There is no difference in subsequent reproductive outcome between these surgical approaches. However, there is a trend towards higher rates of persistent trophoblast associated with laparoscopic surgery for EP [133-136].

Salpingectomy is preferable for tubal pregnancy in patients with uncontrolled bleeding, extensive tubal damage or recurrent EP in the same tube. Salpingostomy is indicated where the patient is haemodynamically stable, wishes to conserve her fertility, if there is an unruptured $\mathrm{EP}<5 \mathrm{~cm}$ in diameter and, especially, when the contralateral tube is absent or damaged [134,137].

Two RCTs have compared salpingectomy and salpingostomy and have recently been published (DEMETER and ESEP). Both reported on reproductive outcomes after treatment of EP by both techniques $[137,138]$. Subsequent fertility, recurrent EP and IUP rates were similar following both approaches. However, persistent trophoblastic tissues were more common with salpingostomy with a relative risk of 15 (95\% CI: 2.0-113.4) for persistence [137].

Hence, Mol et al. (2014) have suggested that salpingectomy should be the procedure of choice in women with tubal pregnancy and a healthy contralateral tube. These recommendations are also adapted by NICE in their guidelines for the management of EP [139]. Furthermore, a study that investigated the preference of patients regarding the type of operation found out that the majority of women preferred salpingectomy to avoid the possibility of another EP. However, the risk of persistent trophoblast was acceptable for these women if compensated by a small increase in the chances of an IUP following surgery [140].

\section{Medical treatment}

Medical management for EP requires effective early diagnosis as its success is inversely correlated with the level of 
serum hCG at diagnosis [130,141-143]. Several agents can be used for the treatment of EP, including methotrexate (MTX), potassium chloride $(\mathrm{KCl})$ and hyperosmolar glucose $[130,144,145]$. The advantages of medical treatment are the avoidance of anaesthesia, surgery and its complications, preservation of tubal patency and function, and possibly cost effectiveness [130,145].

MTX, a cytotoxic drug that destroys rapidly dividing trophoblastic cells, is the most popular medical agent for the treatment of EP. MTX is a folic acid antagonist with metabolism and excretion in the liver and kidney, respectively $[146,147]$. MTX is given as single or multiple doses. The variable dose regimen, which consists of 4 injections, involves the addition of a reduced form of folate, citrovorum, to block the effect of MTX and to prevent adverse effects on other tissues [130,147]. Another treatment protocol with two doses of MTX and a schedule for follow-up for the patient similar to the 'multiple doses' regimen was first proposed in 2007. This protocol does not need the addition of citrovorum for the prevention of the drug side effects [143].

The dose of MTX is calculated according to body surface area $\left(50 \mathrm{mg} / \mathrm{m}^{2}\right)$ or body weight $(1 \mathrm{mg} / \mathrm{kg})$. For most women this will be between 75 and $90 \mathrm{mg}[146,147]$. MTX can be administered by intravenous or intramuscular injection, or by local injection under the guidance of either ultrasound or laparoscopy [141,147]. There is a significant risk of tubal rupture in unsuccessful cases following the use of MTX. Other side effects include abdominal pain due to tubal abortion, stomatitis and diarrhoea, hCG concentrations may rise for up to three days after MTX even in successful cases, and some may need a second dose of MTX $[130,147]$.

Criteria for the use of MTX treatment in EP according to ACOG and NICE guidelines are listed in Table 2. Briefly, methotrexate can be used in haemodynamically stable patients with minimal or no symptoms and who have initial serum hCG concentrations $<5000 \mathrm{IU} / \mathrm{L}$ and EP size $<3.5 \mathrm{~cm}[130,139]$. Patients should be advised to avoid sexual intercourse during treatment, becoming pregnant for 6 months post treatment and excessive exposure to sunlight and alcohol [147].

The treatment with MTX continues until hCG falls by $15 \%$ from its peak concentration within two days for single dose regimen or between day 4 and 7 for the multiple dose/two dose regimens [142,143,146,147]. A serum hCG measurement is performed on day 4 and 7 and a further dose is given if levels have failed to fall by more than $15 \%$ in the multiple dose/two doses regimens [142,143]. Approximately $50 \%$ of the treated patients will not require the full 4 doses in the 'multiple dose' protocol $[130,147]$.

Several studies have compared laparoscopic salpingostomy with MTX, finding MTX to be almost as effective as surgery in terms of success rates and future fertility
Table 2 Criteria of methotrexate (MTX) treatment for ectopic pregnancy (EP)

\begin{tabular}{ll}
\hline MTX for EP & \\
\hline Indications & Haemodynamically stable patients \\
$\cdot$ Minimal or no symptoms & $\cdot$ Serum hCG is $<5000 \mathrm{IU} / \mathrm{L}$ \\
$\cdot$ Ectopic mass $<3.5 \mathrm{~cm}$ \\
$\cdot$ No embryonic cardiac activity \\
$\cdot$ Confirmed diagnosis of ectopic pregnancy \\
$\cdot$ Able to comply with the follow-up \\
$\cdot$ Hemodynamically unstable \\
$\cdot$ Suspected ruptured EP \\
$\cdot$ Heterotopic pregnancy \\
$\cdot$ Pregnancy of unknown location \\
$\cdot$ Breastfeeding \\
$\cdot$ Chronic liver disease \\
$\cdot$ - Renal disease
\end{tabular}

outcomes [135,136,138]. Tubal patency was documented by hysterosalpingography in $78 \%$ of cases and in $65 \%$ of patients who attempted to conceive again. Additionally, the incidence of recurrent EP was relatively low (12\%) and was not significantly different from the observed rate (9\%) with salpingostomy [138].

A meta-analysis reported that the success rate of MTX treatment was $92.7 \%$ and $88.1 \%$ for 'multi-dose' and 'single dose', respectively. The failure rate of 'single dose' protocol was estimated to be about 3 times higher than the 'multiple dose' regimen and the possibility of tubal rupture cannot be excluded even with falling hCG levels [148]. Signs of treatment failure or suspected rupture are indications to stop medical treatment and to shift to surgical management. Signs include haemodynamic instability, increasing abdominal pain regardless of trends in hCG levels, and rapidly increasing hCG concentrations ( $>53 \%$ over 2 days) after two doses or four doses in the 'single' and 'multiple-dose' regimens, respectively [138,143,149-151].

The use of MTX in women with a viable IUP is absolutely contraindicated as the drug would cause miscarriage or congenital malformations $[130,152,153]$. Hence, women with a pregnancy of unknown location (PUL) or HP following IVF-ET should be managed by other means [130]. 
Several other agents have been used for the medical treatment of EP. Sonographically guided local injection of $\mathrm{KCl}$ into the heart of the ectopic fetus can induce cardiac asystole with resolution of EP [154,155]. Hyperosmolar glucose can also be injected into the gestation sac causing local dehydration, necrosis of the trophoblastic tissue and resolution of EP [156,157]. These agents are not associated with fetal malformation but careful consideration should be given before use of hyperosmolar glucose since high doses could increase the risk of bleeding [158].

Recently, two studies have shown that the combination of gefitinib, an orally active epidermal growth factor receptor inhibitor, in combination with a single dose of intramuscular MTX $\left(50 \mathrm{mg} / \mathrm{m}^{2}\right)$ for the treatment of tubal $(\mathrm{n}=12)$ and non-tubal $(\mathrm{n}=8)$ EP was safe and associated with a faster time of EP resolution by $34 \%$ compared with MTX alone [145,159]. The new drug at a daily single dose of $250 \mathrm{mg}$ for seven days was well tolerated by the patients with mild to moderate side effects (e.g. acne/rash and diarrhea) that are known to be associated with gefitinib $[145,159]$. However, gefitinib should only be used for a short and limited 7 days course and women with significant pulmonary comorbidities and Japanese ethnicity should be excluded to decrease/eliminate the risk of interstitial lung disease during the treatment of EP with gefitinib $[145,159]$. RCTs are still needed to confirm the aforementioned findings about the efficacy and safety of combining gefitinib with MTX for the treatment of EP [160].

\section{Expectant management}

When serum hCG is below the discriminatory zone and there is no intra- or extrauterine pregnancy detected by TVS, the pregnancy can be described as being PUL $[121,150]$. Several studies have reported that $44-69 \%$ of PUL resolve spontaneously $[161,162]$ and $8.7-42.8 \%$ of PUL will eventually be diagnosed as early EP which were too small to visualise on initial ultrasound scan $[112,114,163]$.

Expectant management is an option for clinically stable women with serum hCG levels below the discriminatory zone, minimal symptoms associated with either PUL or EP diagnosed on ultrasound $[161,164,165]$. Recent results from an RCT study showed that there is no significant difference in the outcome between MTX and expectant management groups in suitable patients [165]. Another Australian research group announced recently the initiation of a double-blinded multicentre RCT to compare between medical and expectant management for EP but the results has not been published yet [166].

Patients with EP may have an initial 50-66\% increase in $\beta$-hCG concentrations every two days $[112,165]$, mimicking a viable IUP. However the eventual fate of EP is either spontaneous resolution or rupture. This is dependent on the activity of the invading trophoblast tissue, with less aggressive invasion of the trophoblast tissue being associated with spontaneous resolution and more aggressive invasion leading to tubal rupture $[167,168]$. If the serum hCG concentrations increase, intervention is essential or the patients may suffer ruptured EP. On the other hand, for patients at an early stage, with lower gestational age and declining $\beta$-hCG titres, the risk of rupture is small $[161,165]$.

Regular follow-up is essential if expectant management is to be successful and clear information about the importance of compliance with follow-up should be given to the patient. Serial serum hCG concentrations should be followed until they reach $<15 \mathrm{IU} / \mathrm{L}$. If symptoms and signs of EP develop, serum hCG concentrations rise above discriminatory zone or start to plateau, active intervention should be considered $[164,165]$.

\section{Management of heterotopic pregnancy}

The clinical management of HP aims to remove the EP without disturbing the viable IUP. Currently, there is no general consensus on the treatment of HP and the majority of data about its clinical management derive from case reports. Surgical treatment by laparotomy or laparoscopy, injection of feticides with or without fetal reduction by embryo aspiration under ultrasound guidance and expectant management have all been used and reported to be successful in the elimination of the ectopic and preservation of ongoing IUP. The selection of treatment protocol depends on the gestational age at diagnosis, the clinical condition of the patient, the site of ectopic implantation and the experience of the treating physician. In a number of studies, the success rate for rescuing the viable IUP was about $66 \%$ with the remainder ending in early or late miscarriage $[108,122,169]$.

The treatment of HP with a tubal implantation can be performed by laparotomy or laparoscopy and the removal of EP is usually done by salpingectomy and occasionally by salpingostomy [170-174]. For interstitial HP, either medical treatment with local injection of a feticide/embryo reduction for small non-ruptured EP $[158,175,176]$ or cornual resection by laparoscopy or laparotomy in ruptured cases has been used with rescue of the IUP [177-180]. A few studies have also reported the use of expectant management for tubal and interstitial HP $[181,182]$.

Currently, only 14 cases of caesarean scar HP are reported in the literature. The majority of cases were treated medically by local injection of feticides and/or embryo aspiration to rescue the viable IUP except for 2 cases that were treated by laparoscopic and hysteroscopic excision of the EP masses [169,183]. Caesarean scar pregnancy can lead to massive haemorrhage due to uterine rupture and laparotomy followed by wedge excision has been reported to be the preferred approach to 
completely remove the EP, repair the scar and prevention of recurrence $[169,184,185]$.

The majority of cases with cervical HP have been treated conservatively using embryo aspiration with or without local injection of a feticide to preserve the viable IUP [186-188]. Others have successfully used laparoscopy or hysteroscopy for the removal of cervical EP and preservation of the IUP $[189,190]$. Efficacious use of expectant management with continuous close monitoring by TVS was also reported in a few cases [141,188]. However, dilatation and curettage was also found to be necessary in some cases to prevent massive bleeding from cervical pregnancy $[141,188]$.

Ovarian HPs have been managed by wedge resection using laparoscopy or by laparotomy in cases of massive bleeding [191]. Other cases have resulted in salpingooophorectomy due to massive adhesions from a ruptured EP [192]. Other ectopic sites within the abdominal cavity have also been reported and have been treated surgically due to bleeding.

\section{Anti-D immunoglobulin}

According to NICE guidelines, anti-D immunoglobulin at a dose of $250 \mathrm{IU}$ should be given to all non-sensitized women who are rhesus negative and who have EP [139].

\section{Complications of ectopic/heterotopic pregnancy Persistence of trophoblastic tissue}

Persistent trophoblast can follow either laparoscopic or open salpingostomy with reported incidences of $8.1 \%$ and $4 \%$, respectively $[26,137,193,194]$. Risk factors for persistent trophoblastic tissue include high preoperative serum hCG (>3000 IU/L), a rapid preoperative rise in serum hCG and the presence of active tubal bleeding [135,136]. Failure of serum hCG concentrations to decline following initial management is the main diagnostic sign $[135,194]$.

There is no common protocol for the early diagnosis and initiation of treatment of persistent trophoblast [194]. Some have recommended second line treatment if the serum hCG is greater than $10 \%$ of the preoperative level ten days after surgery while others have suggested starting treatment if serum hCG concentrations are $>65 \%$ of their initial levels at 48 hours after surgery. Treatment with a single dose $\left(50 \mathrm{mg} / \mathrm{m}^{2}\right)$ of MTX has been widely used as an alternative to a second surgical procedure. One RCT compared the use of prophylactic MTX at the time of laparoscopic salpingostomy with simple salpingostomy alone and showed a reduction in the rate of persistent trophoblast by $19 \%$ and $14 \%$, respectively [135].

\section{Complications associated with heterotopic pregnancy}

Miscarriage of the viable IUP can follow treatment of a HP. Clayton et al. reported that $84(40.6 \%)$ out of 207 heterotopic cases ended with abortion either spontaneously or induced [195]. HP was 30\% less likely to result in live-birth than an intrauterine only pregnancy following IVF treatment mainly due to the increase in risk for spontaneous and induced abortion in HP by 2 and 10 times compared with singleton IUP, respectively [195].

It is not known whether there is a difference in miscarriage rate between the different types of HP mainly due the rarity of the condition. However, early diagnosis and use of conservative approaches should lead to a better chance of live birth of the co-existing IUP. Hence, a more common site of ectopic implantation (e.g. tubal) may have a better prognosis compared with less frequent sites (e.g. caesarean scar). Future studies are needed to allow comparison of outcomes between the different sites of ectopic implantation and/or different treatment approaches, possibly using a large retrospective survey of IVF registries.

HP can result in complications including severe bleeding and hypovolemic shock, preterm delivery, uterine rupture in cases with caesarean scar implantation or oophorectomy in cases of complicated ovarian implantation $[108,173,183]$.

\section{Effect of ectopic pregnancy and its treatment on subsequent IVF treatment}

The effects of the different lines of treatment for EP, especially radical and medical managements, on subsequent IVF have been described. The significance of salpingectomy in the outcome of subsequent IVF-ET is controversial. It was suggested that salpingectomy could have an adverse effect on ovarian blood supply and subsequently on ovarian steroid production, further follicular development and ovarian response during later IVF cycles due to the disturbance of the vascular and neural connections between the Fallopian tube and ovary $[196,197]$. Many investigators reported significantly fewer follicles and oocytes either from both ovaries or the ipsilateral ovary following salpingectomy [196,198-201].

However more recent retrospective studies that have measured parameters of ovarian response in women who underwent ovulation induction before and after salpingectomy have shown no significant difference in basal FSH levels, oestrogen concentrations, length of stimulation, number of follicles, number of retrieved and fertilised oocyte and quality of embryos between the pre- and postsalpingectomy cycles [202-206].

Results about the requirement for gonadotropins for superovulation are also conflicting. While two studies showed no significant difference [202,207], another described a significant increase in the doses needed following surgery [203]. Ye et al. also reported that serum concentrations of anti-Mullerian hormone were significantly lower and FSH were significantly higher in patients with 
salpingectomy compared to women with no tubal surgery. However there were no significant differences in peak oestradiol concentration, endometrial thickness, number of retrieved oocytes or pregnancy rate between the study groups [207].

Surgical treatment of an EP may result in oophorectomy, either because of an advanced ovarian pregnancy or when tubal pregnancy forms a tubo-ovarian mass due to the presence of extensive pelvic adhesions [192,208]. Women with a single ovary represent a distinct treatment group when ART is needed. Many studies have shown that women who have undergone unilateral oophorectomy respond less well to ovarian stimulation than women with both ovaries, in terms of number of follicles, oestradiol concentrations and number of oocyte retrieved [208-214]. These women also seem to require a higher dose of gonadotropins in order to obtain an adequate ovarian response $[208,211,214]$. However, pregnancy rates in these women were similar to those with intact ovaries in the majority of these studies.

Interestingly, a very recent study has reported that despite the observed overall decrease in the number of follicles and oocytes retrieved seen in women with a single ovary, it appears that the remaining ovary is able to compensate. This was indicated by an increase in the number of follicles and oocytes obtained in patients with a single ovary compared with the response of the ipsilateral ovary of control women during IVF treatment [215]. It appears therefore, that once women with single ovary reach embryo transfer, they can be reassured that their chance of having a child is the same as for women with two ovaries.

MTX is the most accepted alternative to surgical treatment of EP and it was thought that it could potentially compromise female fertility by affecting growing follicles [216,217]. However, it appears that the cytotoxic agent does not have any harmful effect on ovarian reserve as primordial follicles in the ovaries are not affected following treatment with MTX [218-222]. Additionally, there was no significant difference in the ovarian reserve in subsequent IVF cycles between women treated with laparoscopic salpingectomy and those treated with MTX $[206,222,223]$. Hence, it is reassuring to show that the effects of MTX, after it is used as a medical treatment for an EP, does not affect or further compromise a woman's future reproductive potential [206,222,223].

\section{Conclusions}

Ectopic pregnancy is a worldwide medical emergency and its incidence increases following treatment of infertility. Heterotopic pregnancy is also more common following IVF-ET. Early diagnosis and prompt intervention are crucial in order to diminish the morbidity and mortality of EP/HP. The combination of TVS and quantitative serum
hCG is currently the most reliable diagnostic tool. Considering the increase risk of EP/HP subsequent to IVF-ET, follow-up of those patients with a positive pregnancy through early pregnancy is vital and the performance of TVS between weeks 4 and 6 of gestation could allow early detection and conservative management.

Patients with PUL should be closely monitored by serial measurement of serum $\beta$-hCG and repeated ultrasonography. The finding of empty uterus by TVS and persistent increase in hCG concentration should trigger an established protocol for detection of EP. Heterotopic gestation presents a particular diagnostic challenge since the diagnostic value of hCG is limited due to the co-existing viable IUP. The detection of a HP requires a high index of suspicious coupled with TVS by an experienced operator.

Treatment approaches should be tailored according the clinical condition and future fertility requirement of the patient and they should be offered alongside with psychological support. The patient should also be provided with accurate and reliable information on risks of the different treatment approaches and their associated complications and be reassured about the preservation of prospective fertility in subsequent IVF-ET cycles.

New diagnostic tests are needed to better identify those who are at highest risk of developing EP during assisted conception. Special measures might then be adopted in order to avoid this complication, for example by elective salpingectomy or tubal clipping at the cornu as is practised for women with hydrosalpynx. Although the majority of cases can be quickly diagnosed using existing methods, diagnostic dilemmas in the form of PUL or suspected HP still present challenges to the reproductive medicine specialist. Improvement in ultrasound diagnosis of early embryonic localisation and viability, perhaps coupled with novel diagnostic tests for the presence of an extra uterine pregnancy will make the clinicians job easier in the future.

\section{Competing interests}

The authors declare that they have no competing interests.

\section{Authors' contributions}

BR conducted literature search, manuscript outline, preparation and revision. ED participated in literature search and manuscript preparation. WL helped in outlining, drafting, critical review and revision of the manuscript. All authors read and approved the final manuscript.

\section{Acknowledgement}

BR is supported by a grant (11-MED2067-10) from King Abdul Aziz City for Sciences and Technology (KACST) under the National Science, Technology and Innovation Plan.

\section{Author details}

${ }^{1}$ Laboratory Medicine Department, Faculty of Applied Medical Sciences, Umm Al-Qura University, Al-Abdiyah Campus, PO Box 7607, Makkah, KSA. ${ }^{2}$ School of Women's \& Children's Health, University of New South Wales, Sydney, NSW 2031, Australia.

Received: 20 January 2015 Accepted: 3 April 2015

Published online: 12 April 2015 


\section{References}

1. Shaw JL, Diamandis EP, Horne AW, Barnhart K, Bourne T, Messinis IE. Ectopic pregnancy. Clin Chem. 2012;58:1278-85

2. Khan KS, Wojdyla D, Say L, Gulmezoglu AM, Van Look PF. WHO analysis of causes of maternal death: a systematic review. Lancet. 2006;367:1066-74.

3. Mascarenhas MN, Flaxman SR, Boerma T, Vanderpoel S, Stevens GA National, regional, and global trends in infertility prevalence since 1990: a systematic analysis of 277 health surveys. PLoS Med. 2012;9, e1001356.

4. Jurkovic D, Wilkinson $\mathrm{H}$. Diagnosis and management of ectopic pregnancy. BMJ. 2011:342:d3397.

5. Sivalingam VN, Duncan WC, Kirk E, Shephard LA, Horne AW. Diagnosis and management of ectopic pregnancy. J Fam Plann Reprod Health Care. 2011;37:231-40

6. Chang HJ, Suh CS. Ectopic pregnancy after assisted reproductive technology: what are the risk factors? Curr Opin Obstet Gynecol. 2010;22:202-7.

7. Steptoe $P C$, Edwards RG. Birth after the reimplantation of a human embryo. Lancet. 1978;2:366.

8. Myers ER, McCrory DC, Mills AA, Price TM, Swamy GK, Tantibhedhyangkul J, et al. Effectiveness of assisted reproductive technology (ART). Evid Rep Technol Assess (Full Rep). 2008; (167): 1-195

9. Clayton HB, Schieve LA, Peterson HB, Jamieson DJ, Reynolds MA, Wright VC. Ectopic pregnancy risk with assisted reproductive technology procedures. Obstet Gynecol. 2006;107:595-604.

10. Wang LL, Chen X, Ye DS, Liu YD, He YX, Guo W, et al. Misdiagnosis and delayed diagnosis for ectopic and heterotopic pregnancies after in vitro fertilization and embryo transfer. J Huazhong Univ Sci Technolog Med Sci. 2014;34:103-7.

11. Horne AW, Critchley HO. Mechanisms of disease: the endocrinology of ectopic pregnancy. Expert Rev Mol Med. 2012;14, e7.

12. Krishnan T, Winship A, Sonderegger S, Menkhorst E, Horne AW, Brown J, et al. The role of leukemia inhibitory factor in tubal ectopic pregnancy. Placenta. 2013:34:1014-9.

13. Shaw JL, Dey SK, Critchley HO, Horne AW. Current knowledge of the aetiology of human tubal ectopic pregnancy. Hum Reprod Update. 2010;16:432-44.

14. Refaat B. Role of activins in embryo implantation and diagnosis of ectopic pregnancy: a review. Reprod Biol Endocrinol. 2014;12:116.

15. Refaat B, Simpson H, Britton E, Biswas J, Wells M, Aplin JD, et al. Why does the fallopian tube fail in ectopic pregnancy? The role of activins, inducible nitric oxide synthase, and MUC1 in ectopic implantation. Fertil Steril. 2012:97:1115-23.

16. Revel A, Ophir I, Koler M, Achache H, Prus D. Changing etiology of tubal pregnancy following IVF. Hum Reprod. 2008;23:1372-6.

17. Shao R, Nutu M, Weijdegard B, Egecioglu E, Fernandez-Rodriguez J, Karlsson-Lindahl $L$, et al. Clomiphene citrate causes aberrant tubal apoptosis and estrogen receptor activation in rat fallopian tube: implications for tubal ectopic pregnancy. Biol Reprod. 2009;80:1262-71.

18. Jia-Rong Z, Shuang-Di L, Xiao-Ping W. Eutopic or ectopic pregnancy: a competition between signals derived from the endometrium and the fallopian tube for blastocyst implantation. Placenta. 2009;30:835-9.

19. Grady R, Alavi N, Vale R, Khandwala M, McDonald SD. Elective single embryo transfer and perinatal outcomes: a systematic review and meta-analysis. Fertil Steril. 2012;97:324-31.

20. Patil M. Ectopic pregnancy after infertility treatment. J Hum Reprod Sci. 2012:5:154-65.

21. Parashi S, Moukhah S, Ashrafi M. Main risk factors for ectopic pregnancy: a casecontrol study in a sample of Iranian women. Int J Fertil Steril. 2014;8:147-54.

22. Rana P, Kazmi I, Singh R, Afzal M, Al-Abbasi FA, Aseeri A, et al. Ectopic pregnancy: a review. Arch Gynecol Obstet. 2013;288:747-57.

23. Malak M, Tawfeeq T, Holzer H, Tulandi T. Risk factors for ectopic pregnancy after in vitro fertilization treatment. J Obstet Gynaecol Can. 2011;33:617-9.

24. Weigert M, Gruber D, Pernicka E, Bauer P, Feichtinger W. Previous tubal ectopic pregnancy raises the incidence of repeated ectopic pregnancies in in vitro fertilization-embryo transfer patients. J Assist Reprod Genet. 2009;26:13-7.

25. Li C, Meng CX, Zhao WH, Lu HQ, Shi W, Zhang J. Risk factors for ectopic pregnancy in women with planned pregnancy: a case-control study. Eur J Obstet Gynecol Reprod Biol. 2014;181:176-82.

26. Kazandi M, Turan V. Ectopic pregnancy; risk factors and comparison of intervention success rates in tubal ectopic pregnancy. Clin Exp Obstet Gynecol. 2011;38:67-70.
27. Akande V, Turner C, Horner P, Horne A, Pacey A. Impact of Chlamydia trachomatis in the reproductive setting: British Fertility Society Guidelines for practice. Hum Fertil (Camb). 2010;13:115-25.

28. Gradison M. Pelvic inflammatory disease. Am Fam Physician. 2012:85:791-6.

29. Mitchell C, Prabhu M. Pelvic inflammatory disease: current concepts in pathogenesis, diagnosis and treatment. Infect Dis Clin North Am. 2013;27:793-809.

30. Low N, Cassell JA, Spencer B, Bender N, Hilber AM, Van Bergen J, et al. Chlamydia control activities in Europe: cross-sectional survey. Eur J Public Health. 2012:22:556-61.

31. Newby KV, Wallace LM, French DP. How do young adults perceive the risk of chlamydia infection? A qualitative study. Br J Health Psychol. 2012;17:144-54

32. Stephens AJ, Aubuchon M, Schust DJ. Antichlamydial antibodies, human fertility, and pregnancy wastage. Infect Dis Obstet Gynecol. 2011;2011:525182

33. El Hakim EA, Gordon UD, Akande VA. The relationship between serum Chlamydia antibody levels and severity of disease in infertile women with tubal damage. Arch Gynecol Obstet. 2010;281:727-33.

34. Pacchiarotti A, Sbracia M, Mohamed MA, Frega A, Espinola SM, Aragona C. Autoimmune response to Chlamydia trachomatis infection and in vitro fertilization outcome. Fertil Steril. 2009;91:946-8.

35. Jakus S, Neuer A, Dieterle S, Bongiovanni AM, Witkin SS. Antibody to the Chlamydia trachomatis $60 \mathrm{kDa}$ heat shock protein in follicular fluid and in vitro fertilization outcome. Am J Reprod Immunol. 2008;59:85-9.

36. Risser $W L$, Risser JM. The incidence of pelvic inflammatory disease in untreated women infected with Chlamydia trachomatis: a structured review. Int J STD AIDS. 2007;18:727-31.

37. Wallace LA, Scoular A, Hart G, Reid M, Wilson P, Goldberg DJ. What is the excess risk of infertility in women after genital chlamydia infection? A systematic review of the evidence. Sex Transm Infect. 2008;84:171-5.

38. Katz BP, Thom S, Blythe MJ, Arno JN, Caine VM, Jones RB. Fertility in adolescent women previously treated for genitourinary chlamydial infection. Adolescent and Pediartic Gynecology. 1994;7:147-52.

39. El Hakim EA, Epee M, Draycott T, Gordon UD, Akande VA. Significance of positive Chlamydia serology in women with normal-looking Fallopian tubes. Reprod Biomed Online. 2009;19:847-51.

40. Karaer A, Avsar FA, Batioglu S. Risk factors for ectopic pregnancy: a case-control study. Aust N Z J Obstet Gynaecol. 2006;46:521-7.

41. Johnson N, Van Voorst S, Sowter MC, Strandell A, Mol BW. Tubal surgery before IVF. Hum Reprod Update. 2011;17:3.

42. Na ED, Cha DH, Cho JH, Kim MK. Comparison of IVF-ET outcomes in patients with hydrosalpinx pretreated with either sclerotherapy or laparoscopic salpingectomy. Clin Exp Reprod Med. 2012;39:182-6.

43. Schippert C, Soergel P, Staboulidou I, Bassler C, Gagalick S, Hillemanns P, et al. The risk of ectopic pregnancy following tubal reconstructive microsurgery and assisted reproductive technology procedures. Arch Gynecol Obstet. 2012;285:863-71.

44. Audebert A, Pouly JL, Bonifacie B, Yazbeck C. Laparoscopic surgery for distal tubal occlusions: lessons learned from a historical series of 434 cases. Fertil Steril. 2014;102:1203-8.

45. Hjordt Hansen MV, Dalsgaard T, Hartwell D, Skovlund CW, Lidegaard O. Reproductive prognosis in endometriosis. A national cohort study. Acta Obstet Gynecol Scand. 2014;93:483-9.

46. Bogdanskiene G, Berlingieri P, Grudzinskas JG. Association between ectopic pregnancy and pelvic endometriosis. Int J Gynaecol Obstet. 2006;92:157-8.

47. Yang XJ, Xu JY, Shen ZJ, Zhao J. Immunohistochemical alterations of cajal-like type of tubal interstitial cells in women with endometriosis and tubal ectopic pregnancy. Arch Gynecol Obstet. 2013;288:1295-300

48. Hyland A, Piazza KM, Hovey KM, Ockene JK, Andrews CA, Rivard C, et al. Associations of lifetime active and passive smoking with spontaneous abortion, stillbirth and tubal ectopic pregnancy: a cross-sectional analysis of historical data from the Women's Health Initiative. Tob Control. 2014; doi:10.1136/tobaccocontrol-2013-051458.

49. Waylen AL, Metwally M, Jones GL, Wilkinson AJ, Ledger WL. Effects of cigarette smoking upon clinical outcomes of assisted reproduction: a metaanalysis. Hum Reprod Update. 2009;15:31-44.

50. Talbot P, Riveles K. Smoking and reproduction: the oviduct as a target of cigarette smoke. Reprod Biol Endocrinol. 2005;3:52.

51. Shao R. Cigarette smoking effect on oviductal ciliation and ciliogenesis. Fertil Steril. 2013;99, e5. 
52. Shao R, Zou S, Wang X, Feng Y, Brannstrom M, Stener-Victorin E, et al. Revealing the hidden mechanisms of smoke-induced fallopian tubal implantation. Biol Reprod. 2012;86:131.

53. Horne AW, Brown JK, Nio-Kobayashi J, Abidin HB, Adin ZE, Boswell L, et al. The association between smoking and ectopic pregnancy: why nicotine is BAD for your fallopian tube. PLoS One. 2014:9, e89400.

54. Galliano D, Bellver J, Diaz-Garcia C, Simon C, Pellicer A. ART and uterine pathology: how relevant is the maternal side for implantation? Hum Reprod Update. 2015;21:13-38

55. Yoshino O, Hayashi T, Osuga Y, Orisaka M, Asada H, Okuda S, et al. Decreased pregnancy rate is linked to abnormal uterine peristalsis caused by intramural fibroids. Hum Reprod. 2010;25:2475-9.

56. Steptoe PC, Edwards RG. Reimplantation of a human embryo with subsequent tubal pregnancy. Lancet. 1976;1:880-2.

57. Wang L, Qiao J, Li R, Zhen X, Liu Z. Role of endometrial blood flow assessment with color Doppler energy in predicting pregnancy outcome of IVF-ET cycles. Reprod Biol Endocrinol. 2010;8:122.

58. Shao R, Feng Y, Zou S, Weijdegard B, Wu G, Brannstrom M, et al. The role of estrogen in the pathophysiology of tubal ectopic pregnancy. Am J Transl Res. 2012;4:269-78

59. Wang J, Wei Y, Diao F, Cui Y, Mao Y, Wang W, et al. The association between polycystic ovary syndrome and ectopic pregnancy after in vitro fertilization and embryo transfer. Am J Obstet Gynecol. 2013;209:139. e1-9.

60. Allersma T, Farquhar C, Cantineau AE. Natural cycle in vitro fertilisation (IVF) for subfertile couples. Cochrane Database Syst Rev. 2013;8, CD010550.

61. Wu Z, Li R, Ma Y, Deng B, Zhang X, Meng Y, et al. Effect of HCG-day serum progesterone and oestradiol concentrations on pregnancy outcomes in GnRH agonist cycles. Reprod Biomed Online. 2012;24:511-20.

62. Zhang YL, Sun J, Su YC, Guo YH. and Sun YP [Study on the incidence and influences on ectopic pregnancy from embryo transfer of fresh cycles and frozen-thawed cycles]. Zhonghua Fu Chan Ke Za Zhi. 2012;47:655-8.

63. Zhang YL, Sun J, Su YC, Guo YH, Sun YP. Ectopic pregnancy in frozen-thawed embryo transfer: a retrospective analysis of 4,034 cycles and related factors. Syst Biol Reprod Med. 2013;59:34-7.

64. Givens CR, Markun LC, Ryan IP, Chenette PE, Herbert CM, Schriock ED Outcomes of natural cycles versus programmed cycles for 1677 frozen-thawed embryo transfers. Reprod Biomed Online. 2009:19:380-4.

65. Hancke K, More S, Kreienberg R, Weiss JM. Patients undergoing frozen-thawed embryo transfer have similar live birth rates in spontaneous and artificial cycles. J Assist Reprod Genet. 2012;29:403-7.

66. Shen C, Shu D, Zhao X, Gao Y. Comparison of clinical outcomes between fresh embryo transfers and frozen-thawed embryo transfers. Iran J Reprod Med. 2014;12:409-14.

67. Eftekhar M, Rahsepar M, Rahmani E. Effect of progesterone supplementation on natural frozen-thawed embryo transfer cycles: a randomized controlled trial. Int J Fertil Steril. 2013;7:13-20.

68. Stadtmauer L, Silverberg KM, Ginsburg ES, Weiss H, Howard B. Progesterone vaginal ring versus vaginal gel for luteal support with in vitro fertilization: a randomized comparative study. Fertil Steril. 2013;99:1543-9.

69. Baker VL, Jones CA, Doody K, Foulk R, Yee B, Adamson GD, et al. A randomized, controlled trial comparing the efficacy and safety of aqueous subcutaneous progesterone with vaginal progesterone for luteal phase support of in vitro fertilization. Hum Reprod. 2014;29:2212-20.

70. Lockwood G, Griesinger G, Cometti B. Subcutaneous progesterone versus vaginal progesterone gel for luteal phase support in in vitro fertilization: a noninferiority randomized controlled study. Fertil Steril. 2014:101:112-9.

71. Glujovsky D, Pesce R, Fiszbajn G, Sueldo C, Hart RJ, Ciapponi A. Endometria preparation for women undergoing embryo transfer with frozen embryos or embryos derived from donor oocytes. Cochrane Database Syst Rev. 2010; (1):CD006359.

72. van der Linden M, Buckingham K, Farquhar C, Kremer JA, Metwally M. Luteal phase support for assisted reproduction cycles. Cochrane Database Syst Rev. 2011; (10):CD009154.

73. Kaur H, Krishna D, Shetty N, Krishnan S, Srinivas MS, Rao KA. Effect of Pre-ovulatory Single Dose GnRH agonist Therapy on IVF Outcome in GnRH Antagonist Cycles; A Prospective Study. J Reprod Infertil. 2012;13:225-31.

74. Sahin S, Ozay A, Ergin E, Turkgeldi L, Kurum E, Ozornek H. The risk of ectopic pregnancy following GnRH agonist triggering compared with hCG triggering in $\mathrm{GnRH}$ antagonist ivf cycles. Arch Gynecol Obstet. 2015;291:185-91.
75. Youssef MA, Van der Veen F, Al-Inany HG, Griesinger G, Mochtar MH, Aboulfoutouh I, et al. Gonadotropin-releasing hormone agonist versus HCG for oocyte triggering in antagonist assisted reproductive technology cycles. Cochrane Database Syst Rev. 2011; (11):CD008046.

76. Howles CM, Ezcurra D, Homburg R. Ovarian stimulation protocols in assisted reproductive technology: an update. Expert Review of Endocrinology \& Metabolism. 2012;7:319-30.

77. Jun SH, Milki AA. Assisted hatching is associated with a higher ectopic pregnancy rate. Fertil Steril. 2004;81:1701-3.

78. Hagemann AR, Lanzendorf SE, Jungheim ES, Chang AS, Ratts VS, Odem RR. A prospective, randomized, double-blinded study of assisted hatching in women younger than 38 years undergoing in vitro fertilization. Fertil Steril. 2010;93:586-91.

79. Karipcin FS, Moragianni VA, Milette B, Kinzer DR, Thornton KL, Barrett B, et al Effect of steroid and antibiotic treatment during assisted hatching on IVF outcomes. Hum Fertil (Camb). 2012;15:205-9.

80. Wang SS, Sun HX. Blastocyst transfer ameliorates live birth rate compared with cleavage-stage embryos transfer in fresh in vitro fertilization or intracytoplasmic sperm injection cycles: reviews and meta-analysis. Yonsei Med J. 2014;55:815-25

81. Li RR, Dong YZ, Guo YH, Sun YP, Su YC, Chen F. Comparative study of pregnancy outcomes between day 3 embryo transfer and day 5 blastocyst transfer in patients with progesterone elevation. J Int Med Res. 2013;41:1318-25

82. Milki AA, Jun SH. Ectopic pregnancy rates with day 3 versus day 5 embryo transfer: a retrospective analysis. BMC Pregnancy Childbirth. 2003;3:7.

83. Smith LP, Oskowitz SP, Dodge LE, Hacker MR. Risk of ectopic pregnancy following day-5 embryo transfer compared with day-3 transfer. Reprod Biomed Online. 2013;27:407-13.

84. Ishihara O, Kuwahara A, Saitoh H. Frozen-thawed blastocyst transfer reduces ectopic pregnancy risk: an analysis of single embryo transfer cycles in Japan. Fertil Steril. 2011;95:1966-9.

85. Shapiro BS, Daneshmand ST, De Leon L, Garner FC, Aguirre M, Hudson C. Frozen-thawed embryo transfer is associated with a significantly reduced incidence of ectopic pregnancy. Fertil Steril. 2012;98:1490-4.

86. Huang B, Hu D, Qian K, Ai J, Li Y, Jin L, et al. Is frozen embryo transfer cycle associated with a significantly lower incidence of ectopic pregnancy? An analysis of more than 30,000 cycles. Fertil Steril. 2014;102:1345-9.

87. Job-Spira N, Coste J, Bouyer J, Tharaux-Deneux C, Fernandez H. Chromosomal abnormalities and ectopic pregnancy? New directions for aetiological research. Hum Reprod. 1996;11:239-42.

88. Ertzeid $\mathrm{G}$, Storeng R. The impact of ovarian stimulation on implantation and fetal development in mice. Hum Reprod. 2001;16:221-5.

89. Lesny P, Killick SR, Tetlow RL, Robinson J, Maguiness SD. Embryo transfer-can we learn anything new from the observation of junctional zone contractions? Hum Reprod. 1998;13:1540-6.

90. Lesny P, Killick SR, Tetlow RL, Robinson J, Maguiness SD. Uterine junctional zone contractions during assisted reproduction cycles. Hum Reprod Update. 1998:4:440-5.

91. Zhu L, Xiao L, Che HS, Li YP, Liao JT. Uterine peristalsis exerts control over fluid migration after mock embryo transfer. Hum Reprod. 2014;29:279-85.

92. Zhu L, Che HS, Xiao L, Li YP. Uterine peristalsis before embryo transfer affects the chance of clinical pregnancy in fresh and frozen-thawed embryo transfer cycles. Hum Reprod. 2014;29:1238-43.

93. Azem F, Yaron Y, Botchan A, Amit A, Yovel I, David MP, et al. Ectopic pregnancy after in vitro fertilization-embryo transfer (IVF-ET): the possible role of the ET technique. J Assist Reprod Genet. 1993;10:302-4.

94. Nazari A, Askari HA, Check JH, O'Shaughnessy A. Embryo transfer technique as a cause of ectopic pregnancy in in vitro fertilization. Fertil Steril. 1993;60:919-21.

95. Keegan DA, Morelli SS, Noyes N, Flisser ED, Berkeley AS, Grifo JA. Low ectopic pregnancy rates after in vitro fertilization: do practice habits matter? Fertil Steril. 2007;88:734-6.

96. Marcus SF, Brinsden PR. Analysis of the incidence and risk factors associated with ectopic pregnancy following in-vitro fertilization and embryo transfer. Hum Reprod. 1995;10:199-203.

97. Knutzen V, Stratton CJ, Sher G, McNamee PI, Huang TT, Soto-Albors C. Mock embryo transfer in early luteal phase, the cycle before in vitro fertilization and embryo transfer: a descriptive study. Fertil Steril. 1992;57:156-62.

98. Coroleu B, Barri PN, Carreras O, Martinez F, Parriego M, Hereter L, et al. The influence of the depth of embryo replacement into the uterine cavity on 
implantation rates after IVF: a controlled, ultrasound-guided study. Hum Reprod. 2002;17:341-6.

99. Eytan O, Elad D, Jaffa AJ. Evaluation of the embryo transfer protocol by a laboratory model of the uterus. Fertil Steril. 2007;88:485-93.

100. Friedman BE, Lathi RB, Henne MB, Fisher SL, Milki AA. The effect of air bubble position after blastocyst transfer on pregnancy rates in IVF cycles. Fertil Steril. 2011;95:944-7.

101. Rovei V, Dalmasso P, Gennarelli G, Lantieri T, Basso G, Benedetto C, et al. IVF outcome is optimized when embryos are replaced between 5 and $15 \mathrm{~mm}$ from the fundal endometrial surface: a prospective analysis on 1184 IVF cycles. Reprod Biol Endocrinol. 2013;11:114.

102. Cenksoy PO, Ficicioglu C, Yesiladali M, Akcin OA, Kaspar C. The importance of the length of uterine cavity, the position of the tip of the inner catheter and the distance between the fundal endometrial surface and the air bubbles as determinants of the pregnancy rate in IVF cycles. Eur J Obstet Gynecol Reprod Biol. 2014;172:46-50.

103. Pandian Z, Marjoribanks J, Ozturk O, Serour G, Bhattacharya S. Number of embryos for transfer following in vitro fertilisation or intra-cytoplasmic sperm injection. Cochrane Database Syst Rev. 2013;7, CD003416.

104. Kissin DM, Kulkarni AD, Kushnir VA, Jamieson DJ. Number of embryos transferred after in vitro fertilization and good perinatal outcome. Obstet Gynecol. 2014;123:239-47.

105. Chai J, Yeung TW, Lee VC, Li RH, Lau EY, Yeung WS, et al. Live birth rate, multiple pregnancy rate, and obstetric outcomes of elective single and double embryo transfers: Hong Kong experience. Hong Kong Med J. 2014;20:102-6.

106. Chambers GM, Ledger W. The economic implications of multiple pregnancy following ART. Semin Fetal Neonatal Med. 2014;19:254-61.

107. Perkins KM, Boulet SL, Kissin DM, Jamieson DJ. Risk of ectopic pregnancy associated with assisted reproductive technology in the United States, 2001-2011. Obstet Gynecol. 2015;125:70-8.

108. Luo X, Lim CE, Huang C, Wu J, Wong WS, Cheng NC. Heterotopic pregnancy following in vitro fertilization and embryo transfer: 12 cases report. Arch Gynecol Obstet. 2009;280:325-9.

109. Dillon KE, Sioulas VD, Sammel MD, Chung K, Takacs P, Shaunik A, et al. How and when human chorionic gonadotropin curves in women with an ectopic pregnancy mimic other outcomes: differences by race and ethnicity. Fertil Steril. 2012;98:911-6.

110. Wu G, Yang J, Xu W, Yin T, Zou Y, Wang Y. Serum beta human chorionic gonadotropin levels on day 12 after in vitro fertilization in predicting final type of clinical pregnancy. J Reprod Med. 2014;59:161-6.

111. Kao LY, Scheinfeld MH, Chernyak V, Rozenblit AM, Oh S, Dym RJ. Beyond ultrasound: $\mathrm{CT}$ and MRI of ectopic pregnancy. AJR Am J Roentgenol. 2014;202:904-11.

112. Kirk E, Bottomley C, Bourne T. Diagnosing ectopic pregnancy and current concepts in the management of pregnancy of unknown location. Hum Reprod Update. 2014;20:250-61.

113. Murray H, Baakdah H, Bardell T, Tulandi T. Diagnosis and treatment of ectopic pregnancy. CMAJ. 2005;173:905-12.

114. Guha S, Ayim F, Ludlow J, Sayasneh A, Condous G, Kirk E, et al. Triaging pregnancies of unknown location: the performance of protocols based on single serum progesterone or repeated serum hCG levels. Hum Reprod. 2014:29:938-45.

115. Shapiro BS, Daneshmand ST, Restrepo H, Garner FC. Serum HCG measured in the peri-implantation period predicts IVF cycle outcomes. Reprod Biomed Online. 2012;25:248-53.

116. Lawler CC, Budrys NM, Rodgers AK, Holden A, Brzyski RG, Schenken RS. Serum beta human chorionic gonadotropin levels can inform outcome counseling after in vitro fertilization. Fertil Steril. 2011;96:505-7.

117. Kathiresan AS, Cruz-Almeida Y, Barrionuevo MJ, Maxson WS, Hoffman DI, Weitzman VN, et al. Prognostic value of beta-human chorionic gonadotropin is dependent on day of embryo transfer during in vitro fertilization. Fertil Steril. 2011;96:1362-6.

118. Zhang Q, Tang R, Gao X, Zhang B, Chen ZJ. Serum human chorionic gonadotropin level measured 17 days after oocyte retrieval can predict final clinical pregnancy outcomes in IVF/ICSI treatment cycles. J Reprod Med. 2014;59:285-92.

119. Chen ZY, Liu JH, Liang K, Liang WX, Ma SH, Zeng GJ, et al. The diagnostic value of a multivariate logistic regression analysis model with transvaginal power Doppler ultrasonography for the prediction of ectopic pregnancy. J Int Med Res. 2012:40:184-93.
120. Desai D, Lu J, Wyness SP, Greene DN, Olson KN, Wiley CL, et al. Human chorionic gonadotropin discriminatory zone in ectopic pregnancy: does assay harmonization matter? Fertil Steril. 2014;101:1671-4.

121. Kirk E. Ultrasound in the diagnosis of ectopic pregnancy. Clin Obstet Gynecol. 2012;55:395-401.

122. Talbot K, Simpson R, Price N, Jackson SR. Heterotopic pregnancy. J Obstet Gynaecol. 2011;31:7-12.

123. Uysal F, Uysal A, Oztekin DC, Avci MS. Heterotopic quadruplet pregnancy and successful twin outcome. Arch Gynecol Obstet. 2013;288:715-7.

124. Petrides A, Dinglas C, Chavez M, Taylor S, Mahboob S. Revisiting ectopic pregnancy: a pictorial essay. J Clin Imaging Sci. 2014;4:37.

125. Yamamoto R, Murakoshi H, Yamashita Y, Ejima Y, Yoshida S, Motoyama S. Heterotopic pregnancy diagnosed before the onset of severe symptoms: case report. Clin Exp Obstet Gynecol. 2013:40:445-7.

126. Li XH, Ouyang Y, Lu GX. Value of transvaginal sonography in diagnosing heterotopic pregnancy after in-vitro fertilization with embryo transfer. Ultrasound Obstet Gynecol. 2013:41:563-9.

127. Benson CB, Doubilet PM, Peters HE, Frates MC. Intrauterine fluid with ectopic pregnancy: a reappraisal. J Ultrasound Med. 2013;32:389-93.

128. Malhotra R, Bramante RM, Radomski M, Nelson M. Mirror image artifact mimicking heterotopic pregnancy on transvaginal ultrasound: case series. West J Emerg Med. 2014;15:712-4.

129. Chojenta C, Harris S, Reilly N, Forder P, Austin MP, Loxton D. History of pregnancy loss increases the risk of mental health problems in subsequent pregnancies but not in the postpartum. PLoS One. 2014;9, e95038.

130. Bachman EA, Barnhart K. Medical management of ectopic pregnancy: a comparison of regimens. Clin Obstet Gynecol. 2012;55:440-7.

131. Oron G, Tulandi T. A pragmatic and evidence-based management of ectopic pregnancy. J Minim Invasive Gynecol. 2013;20:446-54.

132. Pouly JL, Mahnes H, Mage G, Canis M, Bruhat MA. Conservative laparoscopic treatment of 321 ectopic pregnancies. Fertil Steril. 1986;46:1093-7.

133. Chaudhary P, Manchanda R, Patil VN. Retrospective study on laparoscopic management of ectopic pregnancy. J Obstet Gynaecol India. 2013;63:173-6.

134. Agdi M, Tulandi T. Surgical treatment of ectopic pregnancy. Best Pract Res Clin Obstet Gynaecol. 2009;23:519-27.

135. Mol F, Mol BW, Ankum WM, Van der Veen F, Hajenius PJ. Current evidence on surgery, systemic methotrexate and expectant management in the treatment of tubal ectopic pregnancy: a systematic review and meta-analysis. Hum Reprod Update. 2008;14:309-19.

136. Hajenius PJ, Mol F, Mol BW, Bossuyt PM, Ankum WM, van der Veen F. Interventions for tubal ectopic pregnancy. Cochrane Database Syst Rev. 2007; (1):CD000324.

137. Mol F, Van Mello NM, Strandell A, Strandell K, Jurkovic D, Ross J, et al. Salpingotomy versus salpingectomy in women with tubal pregnancy (ESEP study): an open-label, multicentre, randomised controlled trial. Lancet. 2014:383:1483-9.

138. Fernandez H, Capmas P, Lucot JP, Resch B, Panel P, Bouyer J. Fertility after ectopic pregnancy: the DEMETER randomized trial. Hum Reprod. 2013;28:1247-53.

139. Newbatt E, Beckles Z, Ullman R, Lumsden MA. Ectopic pregnancy and miscarriage: summary of NICE guidance. BMJ. 2012;345, e8136.

140. Van Mello NM, Mol F, Opmeer BC, De Bekker-Grob EW, Essink-Bot ML, Ankum WM, et al. Salpingotomy or salpingectomy in tubal ectopic pregnancy: what do women prefer? Reprod Biomed Online. 2010;21:687-93.

141. Verma U, English D, Brookfield K. Conservative management of nontubal ectopic pregnancies. Fertil Steril. 2011;96:1391-5.

142. Cohen A, Bibi G, Almog B, Tsafrir Z, Levin I. Second-dose methotrexate in ectopic pregnancies: the role of beta human chorionic gonadotropin. Fertil Steril. 2014:102:1646-9.

143. McLaren JF, Barnhart KT, Sammel MD, Appleby DH, Butts SF. Success of the two-dose methotrexate protocol for treatment of ectopic pregnancy in women with a history of prior ectopic pregnancy. J Reprod Med. 2014:59:379-84.

144. Yeh J, Aziz N, Chueh J. Nonsurgical management of heterotopic abdominal pregnancy. Obstet Gynecol. 2013;121:489-95.

145. Horne AW, Skubisz MM, Tong S, Duncan WC, Neil P, Wallace EM, et al. Combination gefitinib and methotrexate treatment for non-tubal ectopic pregnancies: a case series. Hum Reprod. 2014;29:1375-9.

146. Bodur S, Ozdamar O, Kilic S, Gun I. The efficacy of the systemic methotrexate treatment in caesarean scar ectopic pregnancy: A quantitative 
review of English literature. J Obstet Gynaecol. 2014;1-7. doi:10.3109/ 01443615.2014 .954101

147. Cecchino GN, Araujo Junior E, Elito JJ. Methotrexate for ectopic pregnancy: when and how. Arch Gynecol Obstet. 2014;290:417-23.

148. Barnhart KT, Gosman G, Ashby R, Sammel M. The medical management of ectopic pregnancy: a meta-analysis comparing "single dose" and "multidose" regimens. Obstet Gynecol. 2003;101:778-84.

149. Epee-Bekima M, Overton C. Diagnosis and treatment of ectopic pregnancy. Practitioner. 2013;257:15-7.

150. Cohen A, Zakar L, Gil Y, Amer-Alshiek J, Bibi G, Almog B, et al. Methotrexate success rates in progressing ectopic pregnancies: a reappraisal. Am J Obstet Gynecol. 2014;211:128. e1-5.

151. Skubisz M, Dutton P, Duncan WC, Horne AW, Tong S. Using a decline in serum $\mathrm{hCG}$ between days $0-4$ to predict ectopic pregnancy treatment success after single-dose methotrexate: a retrospective cohort study. BMC Pregnancy Childbirth. 2013;13:30.

152. Addar MH. Methotrexate embryopathy in a surviving intrauterine fetus after presumed diagnosis of ectopic pregnancy: case report. J Obstet Gynaecol Can. 2004:26:1001-3.

153. Usta IM, Nassar AH, Yunis KA, Abu-Musa AA. Methotrexate embryopathy after therapy for misdiagnosed ectopic pregnancy. Int J Gynaecol Obstet. 2007;99:253-5.

154. Savelli L, Fabbri F, Di Donato N, De Meis L. Heterotopic interstitial pregnancy successfully treated with ultrasound-guided potassium chloride injection in the ectopic embryo. J Obstet Gynaecol. 2014:34:276-7.

155. Ugurlucan FG, Bastu E, Dogan M, Kalelioglu I, Alanya S, Has R. Management of cesarean heterotopic pregnancy with transvaginal ultrasound-guided potassium chloride injection and gestational sac aspiration, and review of the literature. J Minim Invasive Gynecol. 2012;19:671-3.

156. Allison JL, Aubuchon M, Leasure JD, Schust DJ. Hyperosmolar glucose injection for the treatment of heterotopic ovarian pregnancy. Obstet Gynecol. 2012;120:449-52.

157. Timor-Tritsch IE. Hyperosmolar glucose injection for the treatment of heterotopic ovarian pregnancy. Obstet Gynecol. 2012;120:1212. author reply 1212-3.

158. Wang Y, Ma CH, Qiao J, Chen XN, Liu P. Efficacy of local aspiration in the conservative treatment of live interstitial pregnancy coexisting with live intrauterine pregnancy after in vitro fertilization and embryo transfer. Chin Med J (Engl). 2012;125:1345-8.

159. Skubisz MM, Horne AW, Johns TG, Nilsson UW, Duncan WC, Wallace EM, et al. Combination gefitinib and methotrexate compared with methotrexate alone to treat ectopic pregnancy. Obstet Gynecol. 2013;122:745-51.

160. Tong S, Skubisz MM, Horne AW. Molecular diagnostics and therapeutics for ectopic pregnancy. Mol Hum Reprod. 2015;21:126-35.

161. Rodrigues SP, De Burlet KJ, Hiemstra E, Twijnstra AR, Van Zwet EW, TrimbosKemper TC, et al. Ectopic pregnancy: when is expectant management safe? Gynecol Surg. 2012;9:421-6.

162. Mavrelos D, Nicks H, Jamil A, Hoo W, Jauniaux E, Jurkovic D. Efficacy and safety of a clinical protocol for expectant management of selected women diagnosed with a tubal ectopic pregnancy. Ultrasound Obstet Gynecol. 2013:42:102-7.

163. Kirk E, Bourne T. Predicting outcomes in pregnancies of unknown location. Womens Health (Lond Engl). 2008:4:491-9.

164. Kirk E, Van Calster B, Condous G, Papageorghiou AT, Gevaert O, Van Huffel $\mathrm{S}$, et al. Ectopic pregnancy: using the hCG ratio to select women for expectant or medical management. Acta Obstet Gynecol Scand. 2011:90:264-72.

165. Van Mello NM, Mol F, Verhoeve HR, Van Wely M, Adriaanse AH, Boss EA, et al. Methotrexate or expectant management in women with an ectopic pregnancy or pregnancy of unknown location and low serum hCG concentrations? A randomized comparison. Hum Reprod. 2013;28:60-7.

166. Casikar I, Lu C, Reid S, Bignardi T, Mongelli M, Morris A, et al. Methotrexate vs placebo in early tubal ectopic pregnancy: a multi- centre double-blind randomised trial. Rev Recent Clin Trials. 2012;7:238-43.

167. Daponte A, Deligeoroglou E, Garas A, Pournaras S, Hadjichristodoulou C, Messinis IE. Activin A and follistatin as biomarkers for ectopic pregnancy and missed abortion. Dis Markers. 2013;35:497-503.

168. Kirk E, Papageorghiou AT, Van Calster B, Condous G, Cowans N, Van Huffel $S$, et al. The use of serum inhibin $A$ and activin $A$ levels in predicting the outcome of 'pregnancies of unknown location'. Hum Reprod. 2009;24:2451-6.
169. Litwicka K, Greco E. Caesarean scar pregnancy: a review of management options. Curr Opin Obstet Gynecol. 2013;25:456-61.

170. Fisher SL, Massie JA, Blumenfeld YJ, Lathi RB. Sextuplet heterotopic pregnancy presenting as ovarian hyperstimulation syndrome and hemoperitoneum. Fertil Steril. 2011;95:2431. e1-3.

171. Kumbak B, Ozkan ZS, Simsek M. Heterotopic pregnancy following bilateral tubal ligation: case report. Eur J Contracept Reprod Health Care. 2011;16:319-21.

172. Fukuda T, Inoue H, Toyama Y, Ichida T, Uzawa Y, Monma M, et al. Bilateral tubal and intrauterine pregnancies diagnosed at laparoscopy. J Obstet Gynaecol Res. 2014;40:2114-7.

173. Yu Y, Xu W, Xie Z, Huang Q, Li S. Management and outcome of 25 heterotopic pregnancies in Zhejiang, China. Eur J Obstet Gynecol Reprod Biol. 2014;180:157-61.

174. Gibson KR, Horne AW. Ruptured heterotopic pregnancy: an unusual presentation of an uncommon clinical problem. BMJ Case Rep. 2012; 2012 bcr2012007423. doi:10.1136/bcr-2012-007423.

175. Park HR, Moon MJ, Ahn EH, Baek MJ, Choi DH. Heterotopic quadruplet pregnancy: conservative management with ultrasonographically-guided $\mathrm{KCl}$ injection of cornual pregnancy and laparoscopic operation of tubal pregnancy. Fetal Diagn Ther. 2009;26:227-30.

176. Ghazeeri GS, Phillips OP, Emerson DS, Kutteh WH, Ke RW. Live birth after treatment of a heterotopic cornual pregnancy with fetal intrathoracic KCl. A case report. J Reprod Med. 2002:47:1038-40.

177. Qin L, Li S, Tan S. Laparoscopic loop ligature for selective therapy in heterotopic interstitial and intrauterine pregnancy following in-vitro fertilization and embryo transfer. Int J Gynaecol Obstet. 2008;101:80-1.

178. Aust T, O'Neill A, Cario G. Purse-string suture technique to enable laparoscopic management of the interstitial gestation of a heterotopic pregnancy. Fertil Steril. 2011;95:261-3.

179. Eom JM, Choi JS, Ko JH, Lee JH, Park SH, Hong JH, et al. Surgical and obstetric outcomes of laparoscopic management for women with heterotopic pregnancy. J Obstet Gynaecol Res. 2013;39:1580-6.

180. Alvarez M, Sole M, Devesa M, Fabregas R, Boada M, Tur R, et al. Live birth using vitrified-warmed oocytes in invasive ovarian cancer: case report and literature review. Reprod Biomed Online. 2014:28:663-8.

181. Sentilhes L, Bouet PE, Gromez A, Poilblanc M, Lefebvre-Lacoeuille C, Descamps P. Successful expectant management for a cornual heterotopic pregnancy. Fertil Steril. 2009;91:934. e11-3.

182. Baxi A, Kaushal M, Karmalkar H, Sahu P, Kadhi P, Daval B. Successful expectant management of tubal heterotopic pregnancy. J Hum Reprod Sci. 2010;3:108-10.

183. OuYang Z, Yin Q, Xu Y, Ma Y, Zhang Q, Yu Y. Heterotopic Cesarean Scar Pregnancy: Diagnosis, Treatment, and Prognosis. J Ultrasound Med. 2014:33:1533-7.

184. Litwicka K, Greco E, Prefumo F, Fratelli N, Scarselli F, Ferrero S, et al. Successful management of a triplet heterotopic caesarean scar pregnancy after in vitro fertilization-embryo transfer. Fertil Steril. 2011;95:291. e1-3.

185. Singh K, Soni A, Rana S. Ruptured ectopic pregnancy in caesarean section scar: a case report. Case Rep Obstet Gynecol. 2012;2012:106892.

186. Cho JH, Kwon H, Lee KW. Han WB. Cervical heterotopic pregnancy after assisted reproductive technology successfully treated with only simple embryo aspiration: a case report. J Reprod Med. 2007:52:250-2.

187. Prorocic M, Vasiljevic M. Treatment of heterotopic cervical pregnancy after in vitro fertilization-embryo transfer by using transvaginal ultrasound-guided aspiration and instillation of hypertonic solution of sodium chloride. Fertil Steril. 2007:88:969. e3-5.

188. Kim JW, Park HM, Lee WS, Yoon TK. What is the best treatment of heterotopic cervical pregnancies for a successful pregnancy outcome? Clin Exp Reprod Med. 2012;39:187-92.

189. Demirel LC, Bodur H, Selam B, Lembet A, Ergin T. Laparoscopic management of heterotopic cesarean scar pregnancy with preservation of intrauterine gestation and delivery at term: case report. Fertil Steril. 2009:91:1293. e5-7.

190. Wang CJ, Tsai F, Chen C, Chao A. Hysteroscopic management of heterotopic cesarean scar pregnancy. Fertil Steril. 2010;94:1529. e15-8.

191. Kamath MS, Aleyamma TK, Muthukumar K, Kumar RM, George K. A rare case report: ovarian heterotopic pregnancy after in vitro fertilization. Fertil Steril. 1910;2010(94):e9-11.

192. Headley AJ, Adum V. Naturally occurring heterotopic pregnancy in a multiparous patient: a case report. J Reprod Med. 2013;58:541-4. 
193. Nathorst-Boos J, Hamad R. Risk factors for persistent trophoblastic activity after surgery for ectopic pregnancy. Acta Obstet Gynecol Scand. 2004;83:471-5.

194. Bora SA, Kirk E, Daemen A, Timmerman D, Bourne T. Is serum human chorionic gonadotrophin follow-up necessary after suspected spillage of trophoblast at the time of laparoscopic surgery for ectopic pregnancy? Gynecol Obstet Invest. 2011;71:225-8.

195. Clayton HB, Schieve LA, Peterson HB, Jamieson DJ, Reynolds MA, Wright VC. A comparison of heterotopic and intrauterine-only pregnancy outcomes after assisted reproductive technologies in the United States from 1999 to 2002. Fertil Steril. 2007;87:303-9.

196. Lass A, Ellenbogen A, Croucher C, Trew G, Margara R, Becattini C, et al. Effect of salpingectomy on ovarian response to superovulation in an in vitro fertilization-embryo transfer program. Fertil Steril. 1998;70:1035-8.

197. Sezik M, Ozkaya O, Demir F, Sezik HT, Kaya H. Total salpingectomy during abdominal hysterectomy: effects on ovarian reserve and ovarian stromal blood flow. J Obstet Gynaecol Res. 2007;33:863-9.

198. Dar P, Sachs GS, Strassburger D, Bukovsky I, Arieli S. Ovarian function before and after salpingectomy in artificial reproductive technology patients. Hum Reprod. 2000;15:142-4.

199. Tal J, Paltieli Y, Korobotchka R, Ziskind G, Eibschitz I, Ohel G. Ovarian response to gonadotropin stimulation in repeated IVF cycles after unilateral salpingectomy. J Assist Reprod Genet. 2002;19:451-5.

200. Gelbaya TA, Nardo LG, Fitzgerald CT, Horne G, Brison DR, Lieberman BA. Ovarian response to gonadotropins after laparoscopic salpingectomy or the division of fallopian tubes for hydrosalpinges. Fertil Steril. 2006;85:1464-8.

201. Orvieto R, Saar-Ryss B, Morgante G, Gemer O, Anteby EY, Meltcer S. Does salpingectomy affect the ipsilateral ovarian response to gonadotropin during in vitro fertilization-embryo transfer cycles? Fertil Steril. 2011;95:1842-4.

202. Almog B, Wagman I, Bibi G, Raz Y, Azem F, Groutz A, et al. Effects of salpingectomy on ovarian response in controlled ovarian hyperstimulation for in vitro fertilization: a reappraisal. Fertil Steril. 2011;95:2474-6.

203. Xi W, Gong F, Tang Y, Zhang H, Lu G. Ovarian response to gonadotropins after laparoscopic salpingectomy for ectopic pregnancy. Int J Gynaecol Obstet. 2012;116:93-6.

204. Lin YJ, Ou YC, Huang FJ, Lin PY, Kung FT, Lan KC. Ovarian response to gonadotropins in patients with tubal factor infertility: salpingectomy versus nonsalpingectomy. J Minim Invasive Gynecol. 2013;20:637-41.

205. Ni L, Sadiq S, Mao Y, Cui Y, Wang W, Liu J. Influence of various tubal surgeries to serum antimullerian hormone level and outcome of the subsequent IVF-ET treatment. Gynecol Endocrinol. 2013;29:345-9.

206. Wiser A, Gilbert A, Nahum R, Orvieto R, Haas J, Hourvitz A, et al. Effects of treatment of ectopic pregnancy with methotrexate or salpingectomy in the subsequent IVF cycle. Reprod Biomed Online. 2013;26:449-53.

207. Ye XP, Yang $Y Z$, Sun $X X$. A retrospective analysis of the effect of salpingectomy on serum antiMullerian hormone level and ovarian reserve. Am J Obstet Gynecol. 2015;212:53. e1-10.

208. Hendricks MS, Chin H, Loh SF. Treatment outcome of women with a single ovary undergoing in vitro fertilisation cycles. Singapore Med J. 2010;51:698-701.

209. Khalifa E, Toner JP, Muasher SJ, Acosta AA. Significance of basal follicle-stimulating hormone levels in women with one ovary in a program of in vitro fertilization. Fertil Steril. 1992:57:835-9.

210. Nargund G, Bromhan D. Comparison of endocrinological and clinical profiles and outcome of IVF cycles in patients with one ovary and two ovaries. J Assist Reprod Genet. 1995;12:458-60.

211. Lass A, Paul M, Margara R, Winston RM. Women with one ovary have decreased response to GnRHa/HMG ovulation protocol in IVF but the same pregnancy rate as women with two ovaries. Hum Reprod. 1997;12:298-300.

212. Lass A. The fertility potential of women with a single ovary. Hum Reprod Update. 1999:5:546-50.

213. Asimakopoulos B, Simopoulou M, Al-Hasani S, Nikolettos N. Women with one ovary in in-vitro fertilisation. Folia Med (Plovdiv). 2003;45:25-9.

214. Al-Hasani S, Asimakopoulos B, Nikolettos N, Diedrich K. Comparison of the response to ovarian stimulation between women with one ovary and those with two ovaries, in a program of ICSI/ET. Acta Obstet Gynecol Scand. 2003;82:845-9.

215. Khan Z, Gada RP, Tabbaa ZM, Laughlin-Tommaso SK, Jensen JR, Coddington 3rd CC, et al. Unilateral oophorectomy results in compensatory follicular recruitment in the remaining ovary at time of ovarian stimulation for in vitro fertilization. Fertil Steril. 2014;101:722-7.
216. Maltaris T, Boehm D, Dittrich R, Seufert R, Koelbl H. Reproduction beyond cancer: a message of hope for young women. Gynecol Oncol. 2006;103:1109-21.

217. Stern CJ, Toledo MG, Gook DA, Seymour JF. Fertility preservation in female oncology patients. Aust N Z J Obstet Gynaecol. 2006;46:15-23.

218. Orvieto R, Kruchkovich J, Zohav E, Rabinson J, Anteby EY, Meltcer S. Does methotrexate treatment for ectopic pregnancy influence the patient's performance during a subsequent in vitro fertilization/embryo transfer cycle? Fertil Steril. 2007;88:1685-6.

219. Oriol B, Barrio A, Pacheco A, Serna J, Zuzuarregui JL, Garcia-Velasco JA. Systemic methotrexate to treat ectopic pregnancy does not affect ovarian reserve. Fertil Steril. 2008;90:1579-82.

220. McLaren JF, Burney RO, Milki AA, Westphal LM, Dahan MH, Lathi RB. Effect of methotrexate exposure on subsequent fertility in women undergoing controlled ovarian stimulation. Fertil Steril. 2009;92:515-9.

221. Boots CE, Gustofson RL, Feinberg EC. Does methotrexate administration for ectopic pregnancy after in vitro fertilization impact ovarian reserve or ovarian responsiveness? Fertil Steril. 2013;100:1590-3.

222. Uyar I, Yucel OU, Gezer C, Gulhan I, Karis B, Hanhan HM, et al. Effect of single-dose methotrexate on ovarian reserve in women with ectopic pregnancy. Fertil Steril. 2013;100:1310-3.

223. Hill MJ, Cooper JC, Levy G, Alford C, Richter KS, DeCherney AH, et al. Ovarian reserve and subsequent assisted reproduction outcomes after methotrexate therapy for ectopic pregnancy or pregnancy of unknown location. Fertil Steril. 2014;101:413-9.

\section{Submit your next manuscript to BioMed Central and take full advantage of:}

- Convenient online submission

- Thorough peer review

- No space constraints or color figure charges

- Immediate publication on acceptance

- Inclusion in PubMed, CAS, Scopus and Google Scholar

- Research which is freely available for redistribution 